\title{
Optimization of Multiple Hydraulically Fractured Horizontal Wells in Unconventional Gas Reservoirs
}

\author{
Wei Yu and Kamy Sepehrnoori \\ Department of Petroleum and Geosystems Engineering, The University of Texas at Austin, Austin, TX 78712, USA \\ Correspondence should be addressed to Wei Yu; weiyu@utexas.edu
}

Received 27 May 2013; Accepted 2 August 2013

Academic Editor: Alireza Bahadori

Copyright (C) 2013 W. Yu and K. Sepehrnoori. This is an open access article distributed under the Creative Commons Attribution License, which permits unrestricted use, distribution, and reproduction in any medium, provided the original work is properly cited.

\begin{abstract}
Accurate placement of multiple horizontal wells drilled from the same well pad plays a critical role in the successful economical production from unconventional gas reservoirs. However, there are high cost and uncertainty due to many inestimable and uncertain parameters such as reservoir permeability, porosity, fracture spacing, fracture half-length, fracture conductivity, gas desorption, and well spacing. In this paper, we employ response surface methodology to optimize multiple horizontal well placement to maximize Net Present Value (NPV) with numerically modeling multistage hydraulic fractures in combination with economic analysis. This paper demonstrates the accuracy of numerical modeling of multistage hydraulic fractures for actual Barnett Shale production data by considering the gas desorption effect. Six uncertain parameters, such as permeability, porosity, fracture spacing, fracture half-length, fracture conductivity, and distance between two neighboring wells with a reasonable range based on Barnett Shale information, are used to fit a response surface of NPV as the objective function and to finally identify the optimum design under conditions of different gas prices based on NPV maximization. This integrated approach can contribute to obtaining the optimal drainage area around the wells by optimizing well placement and hydraulic fracturing treatment design and provide insight into hydraulic fracture interference between single well and neighboring wells.
\end{abstract}

\section{Introduction}

The combination of horizontal drilling and multistage hydraulic fracturing technology has made possible the current flourishing gas production from shale gas reservoirs in the United States, as well as the global fast growing investment in shale gas exploration and development. Multiple transverse hydraulic fractures are generated when all wellbores are drilled in the direction of the minimum horizontal stress. Maximizing the total stimulated reservoir volume (SRV) plays a major role in successful economic gas production. The unprecedented growth of shale reservoirs has brought a new perspective and focus to the optimization of multiwell placement in the same pad. Drilling multiple horizontal wells from a single pad has increasingly become a common approach for developing shale reservoirs due to significant cost, time, and environmental savings. The surface footprint is reduced greatly by drilling multi-well from the same pad due to minimizing the number of surface locations required while increasing the bottom hole contact of the shale resource [1]. Zipper fracturing (zipper-frac) and simultaneous fracturing (simul-frac) [2], where two adjacent horizontal wells are hydraulically fractured alternatingly and simultaneously, respectively, are two commonly used hydraulic fracturing techniques to stimulate multi-well from the same pad. Although hydraulic fractures improve gas production from shale gas wells, the cost of operation is expensive. Long laterals require greater volume of liquids and proppants which contribute to greater cost [3]. The well economics is also sensitive to well performance and natural gas price due to higher drilling and completion costs. Therefore, optimizing well parameters such as well number and well distance in conjunction with hydraulic fracture parameters, such as fracture spacing and fracture half-length based on economic analysis, are very important, especially in the current environment of low natural gas prices.

Optimization of multi-well placement is primarily valuable for overall project economic viability and minimizing 


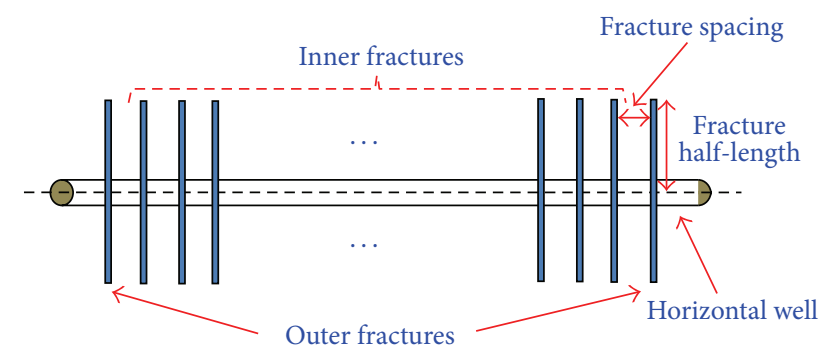

FIGURE 1: A sketch of multiple hydraulic fractured horizontal shale gas well.

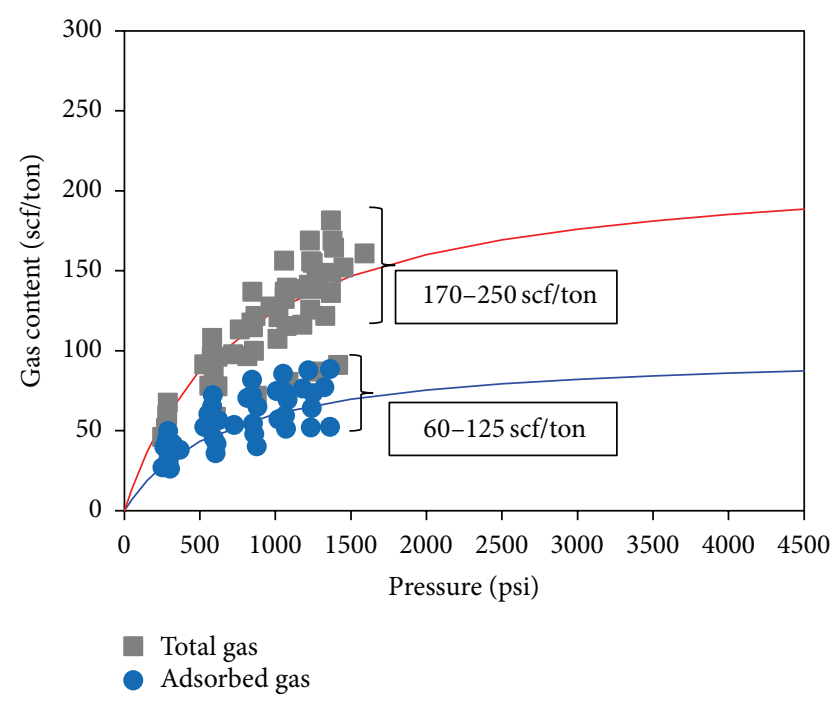

FIGURE 2: Adsorption isotherms for Barnett Shale core samples [4].

the risks of well collision in shale gas reservoirs. Closer well placement will result in stimulated reservoir volume intersects, leading to well competition and penalizing overall production [5]. However, only recently there have been limited studies of optimizing fracturing design together with multiwell placement simultaneously. Esmaili et al. [6] defined three types of horizontal well based on the number of neighboring wells for sharing drainage area when drilling multiple wells from a pad. Rafiee et al. [7] proposed a new design for two horizontal wells by the modification of the traditional zipperfrac and demonstrated this new design maximized reservoir contact and improved well performance when compared to the original zipper-frac design from both rock mechanics and fluid production aspects. However, such a design assumed a larger fracture spacing of $500 \mathrm{ft}$ and did not optimize well placement and fracture spacing simultaneously to obtain the optimal design for economic gas production. Díaz de Souza et al. [8] did sensitivity studies of three different wells placement with 2, 3, and 4 horizontal wells within the same stimulation volume in the Haynesville Shale to obtain the optimal well spacing. They stated that four horizontal wells with a well distance of $660 \mathrm{ft}$ was a near-optimal solution for this reservoir. However, critical parameters for developing a play economically, such as fracture spacing and fracture

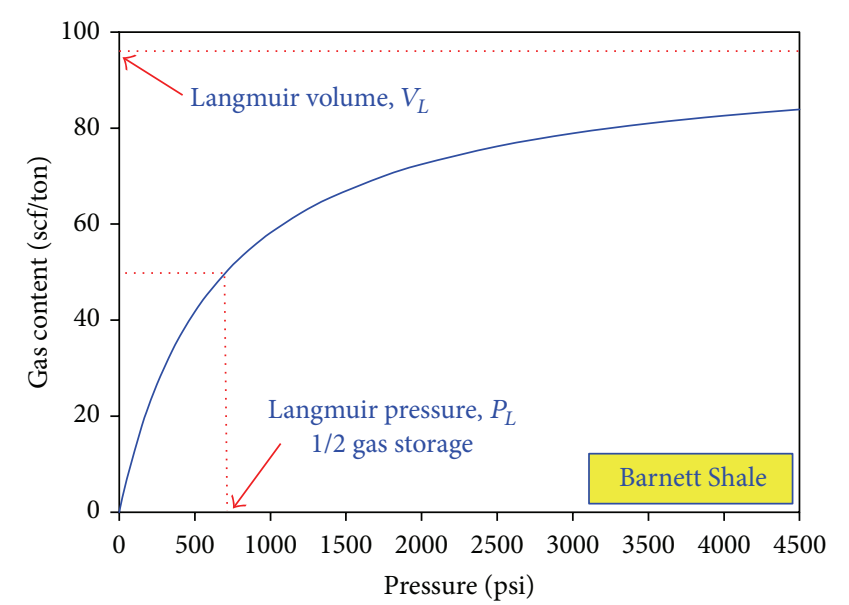

FIgURE 3: Langmuir isotherm curve for Barnett Shale $\left(V_{L}=\right.$ $96 \mathrm{scf} / \mathrm{ton}, P_{L}=650 \mathrm{psi}$, and $\rho_{B}=2.58 \mathrm{~g} / \mathrm{cm}^{3}$ ).

half-length, have not been considered for optimization based on optimal well spacing. Harpel et al. [9] reported that well spacing becomes tighter in parts of the Fayetteville Shale from $600 \mathrm{ft}$ to $400 \mathrm{ft}$ or $300 \mathrm{ft}$, leading to fluid and proppant volume reductions, while further optimization of stimulation design, especially fracture half-length, is very much required for future development. Ramakrishnan et al. [10] suggested that it is particularly challenging to optimize the stimulation treatment in a multi-well design drilled with few hundreds feet of spacing between one another to maximize coverage around each horizontal well, because the optimization process involves perforation and stage placements, sequential stimulation of these wells, fluid and proppant schedules, treatment rates, and application of diversion technology in an effort to achieve effective stimulation along these wells and between the wells. Hence, a detailed study and a comprehensive approach for optimization of fracturing design and multi-well placement are still significantly necessary.

In this paper, we employed response surface methodology to build the response surface in terms of NPV with six parameters such as reservoir porosity, permeability, fracture half-length, fracture conductivity, fracture spacing, and well distance from Barnett Shale, to obtain the best economic scenario for a given range of these influential parameters. The effect of gas desorption is integrated in the numerical modeling of multistage hydraulic fractures. The impact of different gas prices is also taken into account for the optimization process. The goal of this work is to provide insights into the effective exploitation of shale gas reservoirs via optimization of the fracturing design and multiple wells placement simultaneously.

\section{Shale Gas Reservoir Modeling}

Given the complex nature of hydraulic fracture growth and the very low permeability of the matrix rock in shale gas reservoirs, coupled with the predominance of horizontal completions, reservoir simulation is the preferred method to predict and evaluate well performance [11-13]. Local grid 


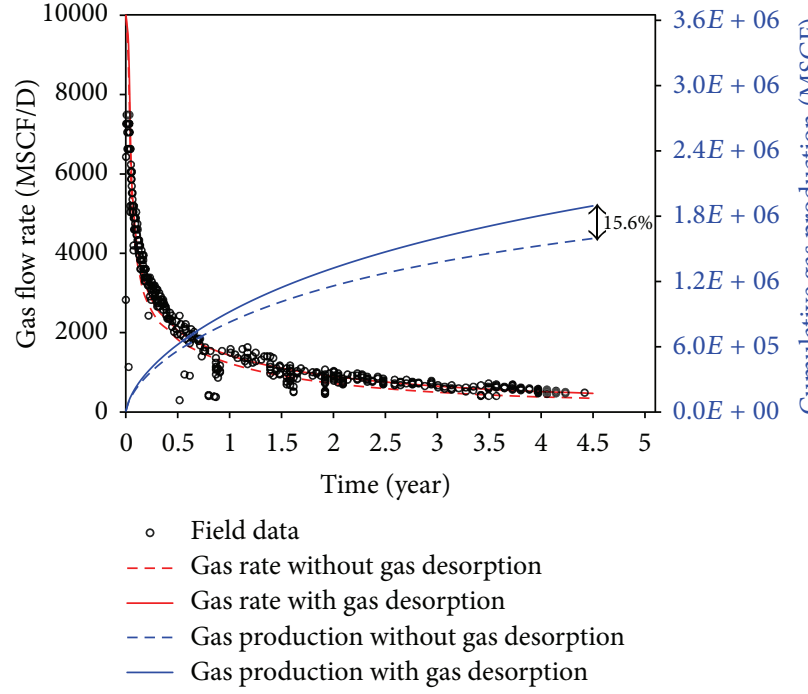

(a) Gas production for a 4.5-year period

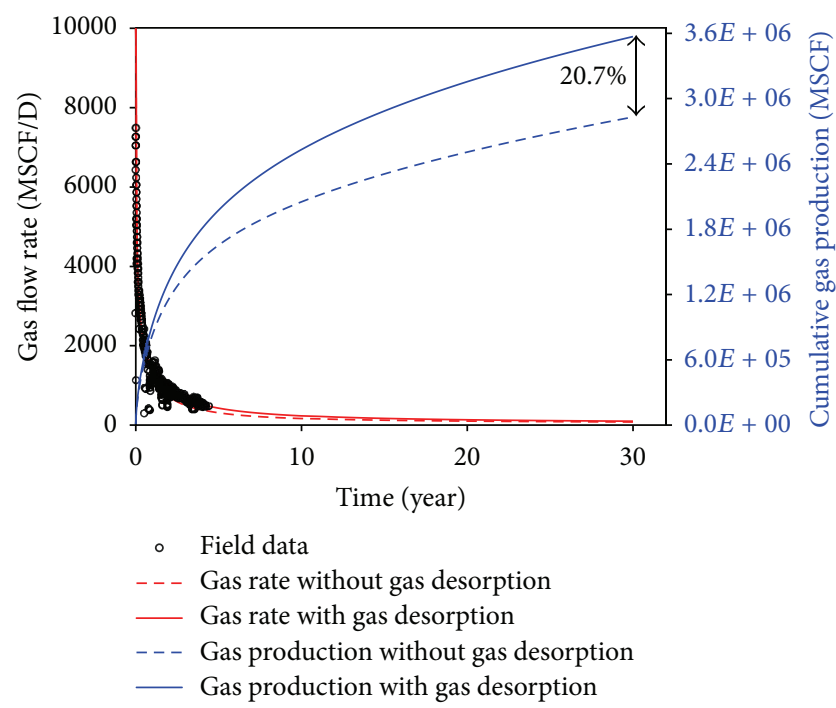

(b) Gas production for a 30-year period

FIGURE 4: History matching of Barnett Shale with and without gas desorption effect.

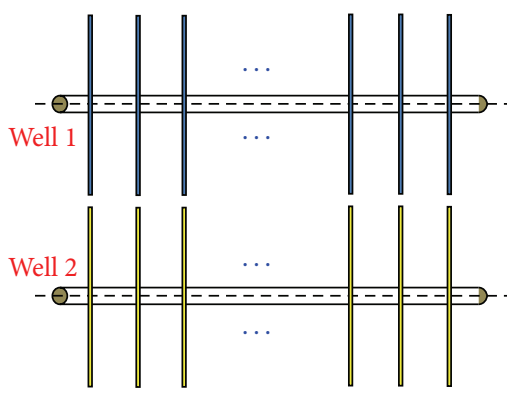

(a) Scenario 1: aligning fracturing

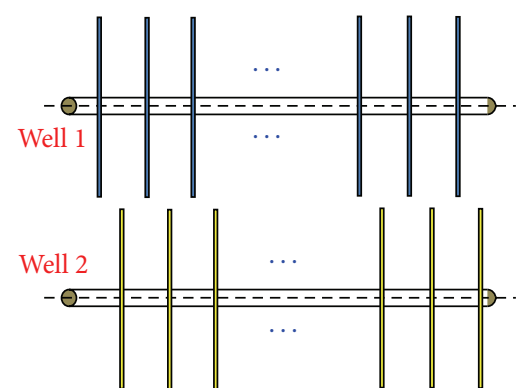

(b) Scenario 2: alternating fracturing

FIGURE 5: Two scenarios of multiple horizontal well placement.

refinement with logarithmic cell spacing is used in the simulation to accurately model flow from the shale to the fracture, that is, properly incorporate the transient flow behavior from the matrix to the fracture. In a block, the hydraulic fracture is explicitly modeled; moreover, the matrix is described as some subcells whose size increases logarithmically, while moving away from the hydraulic fracture to properly simulate the large pressure drop between the matrix and the fracture. In addition, a dual permeability grid is used to allow simultaneous matrix-to-matrix and fracture-to-fracture flows. This method can accurately and efficiently model transient gas production from hydraulic fractures of the horizontal wells in shale gas reservoirs $[14,15]$. The reservoir is assumed to be homogeneous and the fractures evenly spaced, with stressindependent porosity and permeability. It is assumed that there is no water flow in the reservoir modeling of shale gas. In our simulation, gas is only flowing into the wellbore through the hydraulic fractures, that is, no matrix-wellbore communication. The turbulent gas flow due to high gas flow rate in hydraulic fractures is modeled as non-Darcy flow. The non-Darcy Beta factor, used in the Forchheimer number, is determined using a correlation proposed by Evans and Civan [16] as follows:

$$
\beta_{(f)}=\frac{1.485 E 9}{K^{1.021}},
$$

where the unit of $K$ is $\mathrm{md}$ and the unit of $\beta$ is $\mathrm{ft}^{-1}$. The $\beta(f)$ correlation was obtained using over 180 data points including those for propped fractures and was found to match the data very well with the correlation coefficient of 0.974 [14]. This equation is implemented into the numerical model and used for accounting for non-Darcy flow in hydraulic fractures. Figure 1 is a diagram of typical shale gas completion design with a multistage hydraulic fracture treatment, which illustrates several important geometric fracture parameters, such as outer fractures, inner fractures, fracture spacing, and fracture half-length.

\section{Economic Model}

NPV is one of the most common methods used to evaluate the economic viability of investing a project. It is referred to 


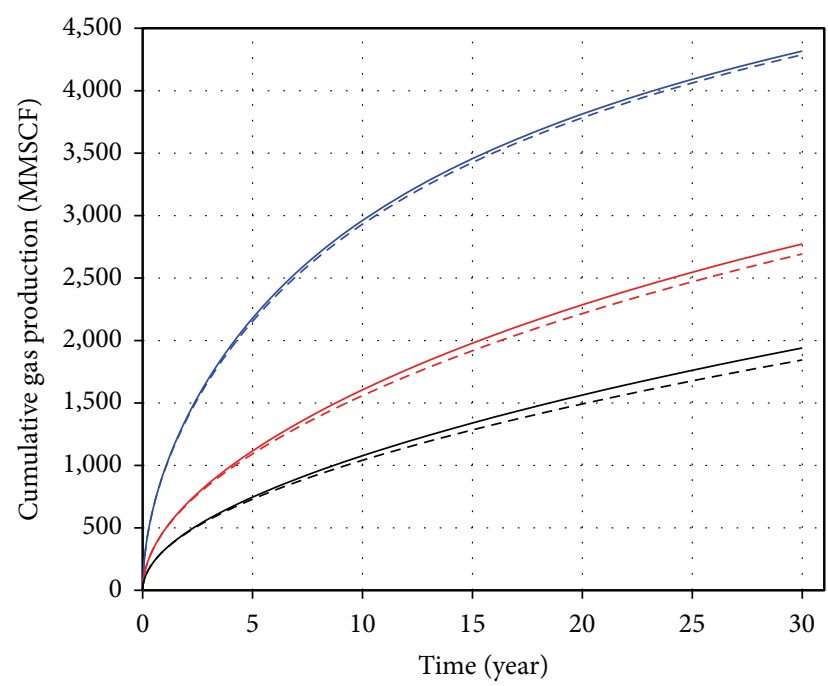

— Scenario 2: fracture spacing $200 \mathrm{ft}$

- - - Scenario 1: fracture spacing $200 \mathrm{ft}$

- Scenario 2: fracture spacing $400 \mathrm{ft}$

- - - Scenario 1: fracture spacing $400 \mathrm{ft}$

- Scenario 2: fracture spacing $600 \mathrm{ft}$

- - - Scenario 1: fracture spacing $600 \mathrm{ft}$

FIGURE 6: Comparison of cumulative gas production.

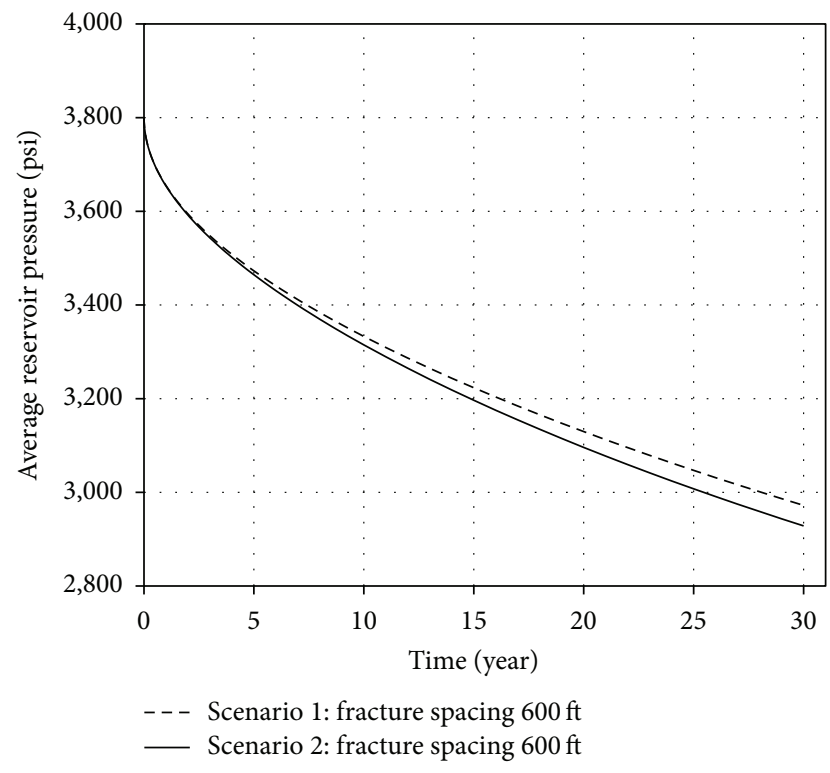

FIGURE 7: Comparison of average reservoir pressure.

the sum of all cash flows discounted to a specific point in time at the investor's minimum discount rate. The correlation between the present value $P$ and the future value $F$ is

$$
P=\frac{F}{(1+i)^{n}}
$$

where $i$ is the currency escalation rate or interest rate; $n$ is the number of periods.
The NPV is calculated using the following expression:

$$
\begin{aligned}
\mathrm{NPV}= & \sum_{j=1}^{n} \frac{\left(V_{F}\right)_{j}}{(1+i)^{j}}-\sum_{j=1}^{n} \frac{\left(V_{o}\right)_{j}}{(1+i)^{j}} \\
& -\left(\mathrm{FC}+\sum_{k=1}^{N}\left(C_{\text {well }}+C_{\text {fracture }}\right)\right),
\end{aligned}
$$

where $V_{F}$ is future value of production revenue for a fracture reservoir; $V_{o}$ is future value of production revenue for an unfractured reservoir; FC is the total fixed cost; $C_{\text {well }}$ is the cost of one horizontal well; $C_{\text {fracture }}$ is the cost of hydraulic fracture in a horizontal well; $N$ is the number of horizontal wells. The costs of well and fracture used in the economic analysis are based on the work of Schweitzer and Bilgesu [17], as shown in Table 1.

\section{Langmuir Isotherm}

Gas shales are organic-rich formations. Gas storage in the shale is mainly divided into free gas in natural fractures and matrix pore structure and adsorbed gas in organic materials. Langmuir isotherm is widely used to describe the gas adsorption phenomenon. The amount of gas stored in shale is often described by Langmuir equation:

$$
G_{s}=\frac{V_{L} P}{P+P_{L}},
$$

where $G_{s}$ is the gas content in scf/ton, $V_{L}$ is the Langmuir volume in scf/ton, $P_{L}$ is the Langmuir pressure in psi, and $P$ is pressure in psi. The bulk density of shale $\left(\rho_{B}\right)$ is needed to convert the typical gas content in scf/ $/ \mathrm{ft}^{3}$ to $\mathrm{scf} /$ ton. Langmuir pressure and Langmuir volume are two key parameters. Langmuir volume is referred to as the gas volume at the infinite pressure representing the maximum storage capacity for gas; Langmuir pressure is referred to as the pressure corresponding to one-half Langmuir volume. As the reservoir pressure is decreased, gas is desorbed from the surface of the matrix. Figure 2 shows a graph of gas content with pressure for the adsorbed gas and total gas used for Barnett Shale [4]. Both free gas and adsorbed gas add together to generate the total gas content. In Barnett Shale, the adsorbed gas is approximately $46 \%$ of the total gas. Contrary to conventional gas reservoirs, the amount of gas desorption in the matrix is commonly described by the Langmuir isotherm in a range of reservoir pressures. The Langmuir isotherm of the Barnett Shale used in this study is illustrated in Figure 3. It is clearly shown that higher Langmuir pressure releases more adsorbed gas and results in higher gas production. Generally, in early stage of production, when reservoir pressure is high, the gas desorption contribution to the gas production is insignificant; however, for long-term production, it is necessary to account for gas desorption, based on a laboratory measured isotherm due to the more substantial pressure depletion, resulting in more gas desorption. CMG [18] was used to model the effect of gas desorption from a shale gas reservoir in a black oil model with a technique developed by Seidle and Arri [19]. 
TABLE 1: Economic data for NPV calculation.

\begin{tabular}{|c|c|c|c|c|c|}
\hline Horizontal well length (ft) & Cost $(\$)$ & Fracture half-length per stage (ft) & Cost $(\$)$ & Parameter & Value \\
\hline 1,000 & $2,000,000$ & 250 & 100,000 & Gas Price & $\$ 3,4,5 / \mathrm{MSCF}$ \\
\hline 2,000 & $2,100,000$ & 500 & 125,000 & Interest rate & $10.0 \%$ \\
\hline 3,000 & $2,200,000$ & 750 & 150,000 & Royalty tax & $12.5 \%$ \\
\hline 4,000 & $2,300,000$ & 1,000 & 175,000 & & \\
\hline
\end{tabular}

TABle 2: Parameters used in history matching.

\begin{tabular}{|c|c|c|}
\hline Parameter & Value(s) & Unit \\
\hline The model dimensions & $3,000$ (length) $\times 1,500$ (width $) \times 300$ (height $)$ & $\mathrm{ft}$ \\
\hline Initial reservoir pressure & 2950 & psi \\
\hline Bottom hole pressure (BHP) & 500 & psi \\
\hline Production time & 30 & year \\
\hline Reservoir temperature & 150 & ${ }^{\circ} \mathrm{F}$ \\
\hline Gas viscosity & 0.0201 & $\mathrm{cp}$ \\
\hline Initial gas saturation & 0.70 & fraction \\
\hline Total compressibility & $3 \times 10^{-6}$ & $\mathrm{Psi}^{-1}$ \\
\hline Matrix permeability & 0.00015 & $\mathrm{md}$ \\
\hline Matrix porosity & 0.06 & fraction \\
\hline Fracture conductivity & 1 & md-ft \\
\hline Fracture half-length & 155 & $\mathrm{ft}$ \\
\hline Fracture spacing & 100 & $\mathrm{ft}$ \\
\hline Fracture height & 300 & $\mathrm{ft}$ \\
\hline Horizontal well length & 2968 & $\mathrm{ft}$ \\
\hline Number of fractures & 28 & number \\
\hline
\end{tabular}

TABLE 3: Parameters used in multiwell modeling.

\begin{tabular}{lcc}
\hline Parameter & Value $(\mathrm{s})$ & Unit \\
\hline The model dimensions & 5,000 (length) $\times 1,600($ width $) \times 200$ (height) & $\mathrm{ft}$ \\
Initial reservoir pressure & 3800 & $\mathrm{psi}$ \\
BHP & 500 & $\mathrm{psi}$ \\
Production time & 30 & $\mathrm{year}$ \\
Reservoir temperature & 0.0201 & ${ }^{\circ} \mathrm{F}$ \\
Gas viscosity & 0.70 & $\mathrm{cp}$ \\
Initial gas saturation & $3 \times 10^{-6}$ & $\mathrm{fraction}$ \\
Total compressibility & 0.0001 & $\mathrm{Psi}{ }^{-1}$ \\
Matrix permeability & 0.06 & $\mathrm{md}$ \\
Matrix porosity & 50 & $\mathrm{fraction}$ \\
Fracture conductivity & 300 & $\mathrm{md}-\mathrm{ft}$ \\
Fracture half-length & $200,400,600$ & $\mathrm{ft}$ \\
Fracture spacing & 200 & $\mathrm{ft}$ \\
Fracture height & 3600 & $\mathrm{ft}$ \\
Horizontal well length per well & $18,9,6$ & $\mathrm{ft}$ \\
Number of fractures per well & 2 & number \\
Number of wells & 620 & $\mathrm{number}$ \\
Well distance & & $\mathrm{ft}$ \\
\hline
\end{tabular}




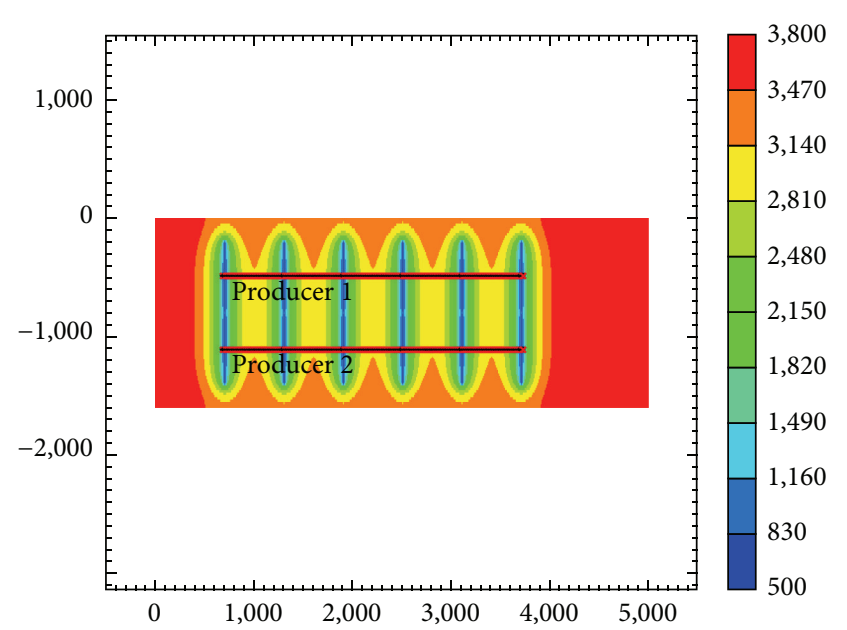

(a) Scenario 1: aligning fracturing

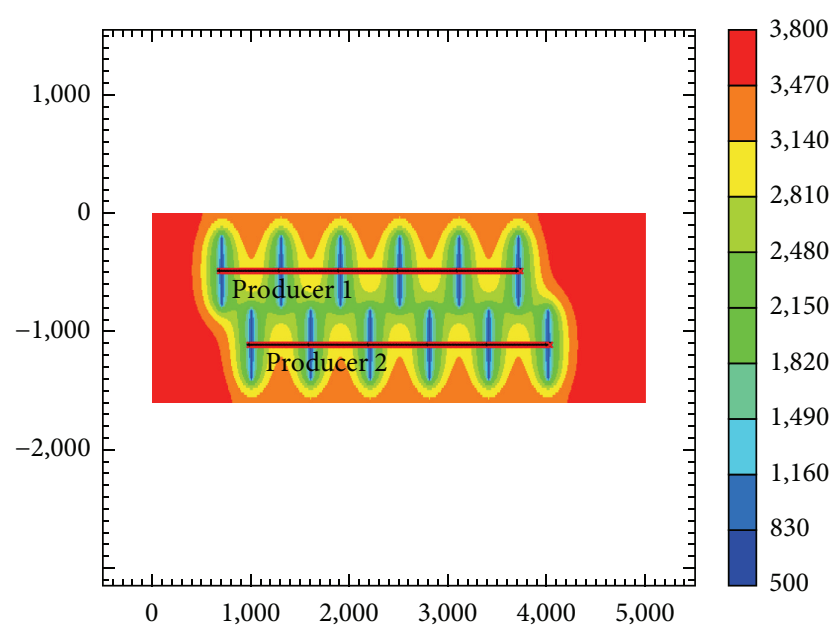

(b) Scenario 2: alternating fracturing

FIgURE 8: Pressure distribution at 30 years of gas production.

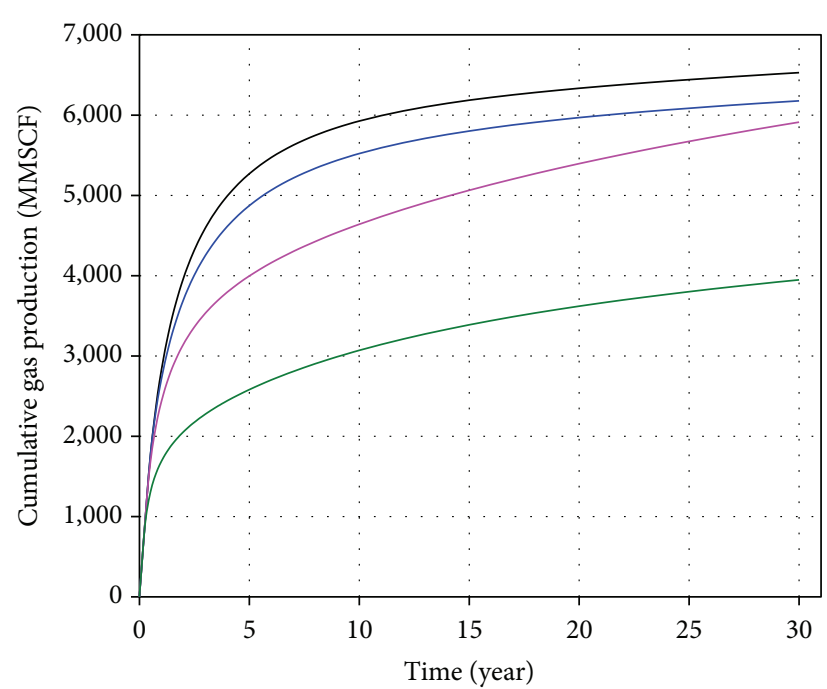

- Case 7: fracture spacing $40 \mathrm{ft}$, fracture half-length $400 \mathrm{ft}$

- Case 13: fracture spacing $60 \mathrm{ft}$, fracture half-length $400 \mathrm{ft}$

- Case 20: fracture spacing $80 \mathrm{ft}$, fracture half-length $200 \mathrm{ft}$

_ Case 19: fracture spacing $100 \mathrm{ft}$, fracture half-length $200 \mathrm{ft}$

FIGURE 9: Cumulative gas production of 30 run cases for a 30-year period.

A Langmuir isotherm is replicated by a black oil model's solution gas ratio to include the effect of gas desorption in shale.

\section{History Matching for Barnett Shale}

Published average reservoir data for a Barnett Shale well were used for history matching [20]. In this case, the well was stimulated by a multistage fracturing with a single, perforated interval for each stage. In this simulation study, we set up a reservoir with a volume of $3000 \mathrm{ft} \times 1500 \mathrm{ft} \times 300 \mathrm{ft}$. The fracture spacing and half-length are set at $100 \mathrm{ft}$ and $150 \mathrm{ft}$,

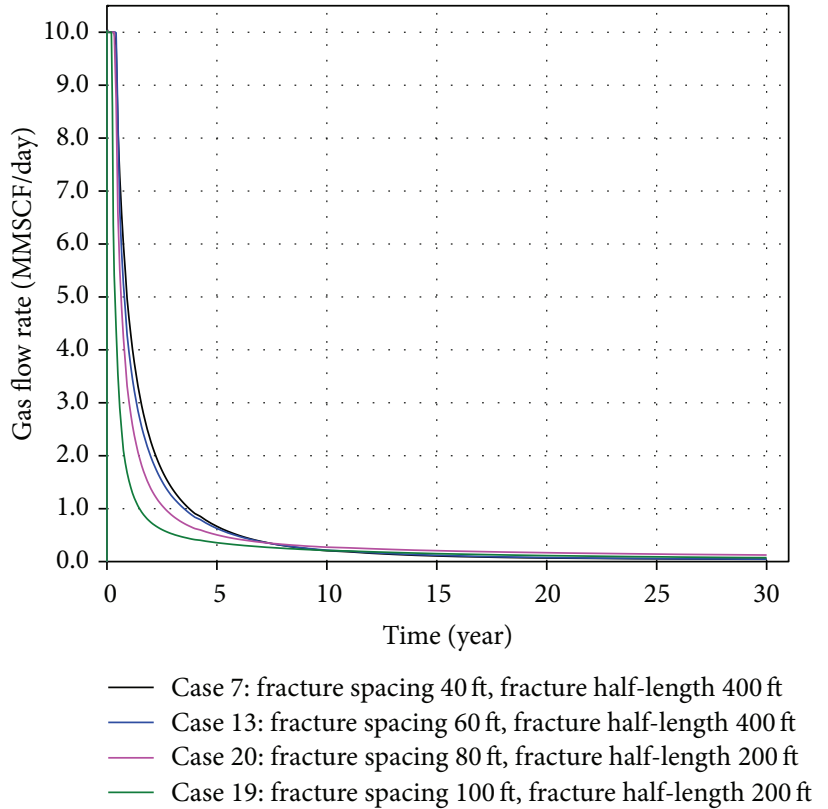

Figure 10: Gas flow rate of 30 run cases for a 30 -year period.

respectively, and the number of fractures is 28 . Detailed reservoir information about this section of the Barnett Shale is listed in Table 2. The reservoir is assumed to be homogeneous and the fractures evenly spaced, with stress-independent porosity and permeability. Only gas is flowing in the reservoir, which is assumed to behave as non-Darcy flow. The history matching of field data is presented in Figure 4(a). It shows a more reasonable match between the numerical simulation results and the actual field gas flow data, considering the effect of gas desorption, contributing to $15.6 \%$ of total gas production at around 4.5 years of gas production. In addition, Figure 4(b) shows the forecasting of gas production for a 30 year period with and without considering gas desorption. 


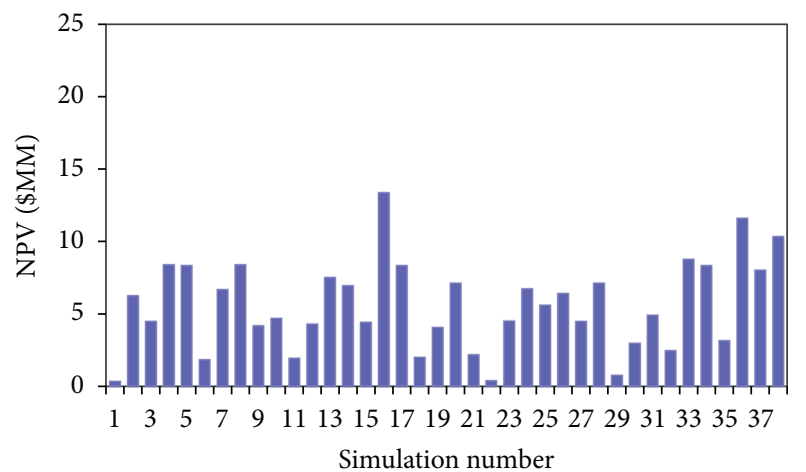

(a) Gas price of $\$ 3 / \mathrm{MSCF}$

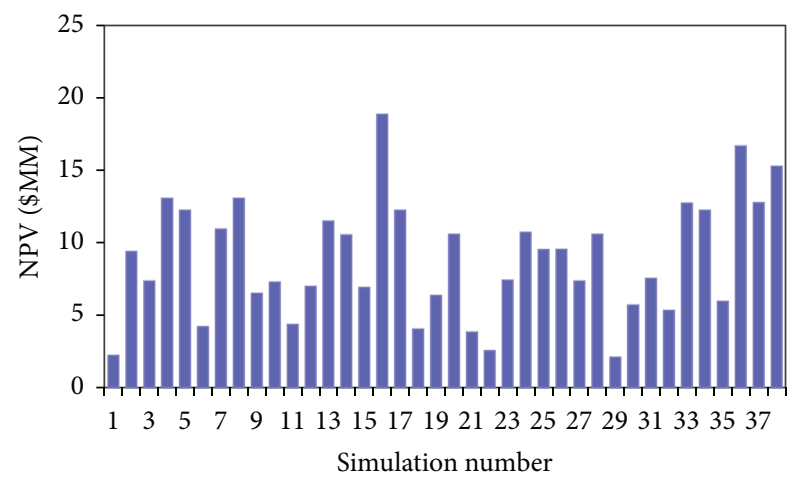

(b) Gas price of $\$ 4 / \mathrm{MSCF}$

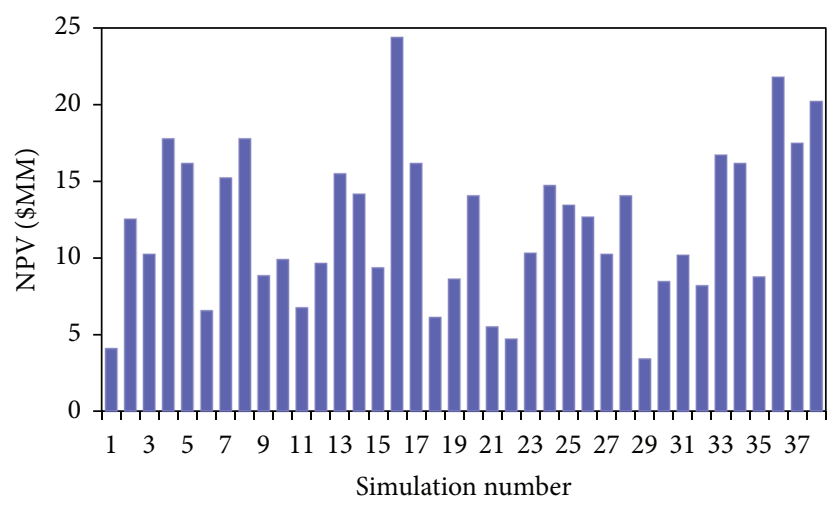

(c) Gas price of $\$ 5 / \mathrm{MSCF}$

FIGURE 11: NPVs of 38 simulation cases at 30 years of gas production with different gas prices.

TABLE 4: Parameters used in multiwell optimization.

\begin{tabular}{|c|c|c|}
\hline Parameter & Value(s) & Unit \\
\hline The model dimensions & $5,000$ (length) $\times 2,000$ (width $) \times 200$ (height $)$ & $\mathrm{ft}$ \\
\hline Initial reservoir pressure & 3800 & psi \\
\hline BHP & 500 & psi \\
\hline Production time & 30 & year \\
\hline Reservoir temperature & 180 & ${ }^{\circ} \mathrm{F}$ \\
\hline Gas viscosity & 0.0201 & $\mathrm{cp}$ \\
\hline Initial gas saturation & 0.70 & fraction \\
\hline Total compressibility & $3 \times 10^{-6}$ & $\mathrm{Psi}^{-1}$ \\
\hline Fracture height & 200 & $\mathrm{ft}$ \\
\hline Horizontal well length per well & 3500 & $\mathrm{ft}$ \\
\hline Number of wells & 2 & number \\
\hline
\end{tabular}

TABLE 5: Uncertainty parameters in this study.

\begin{tabular}{lcccc}
\hline Parameters & Coded symbol & Minimum $(-1)$ & Maximum $(+1)$ & Unit \\
\hline Porosity & A & 0.04 & 0.08 & 0.0005 \\
Permeability & B & 0.00005 & 400 & fraction \\
Fracture half-length & C & 200 & 50 & $\mathrm{md}$ \\
Fracture conductivity & $\mathrm{D}$ & 1 & 100 & $\mathrm{ft}$ \\
Fracture spacing & $\mathrm{E}$ & 50 & $\mathrm{md}-\mathrm{ft}$ \\
Well distance & $\mathrm{F}$ & 500 & 1000 & $\mathrm{ft}$ \\
\hline
\end{tabular}




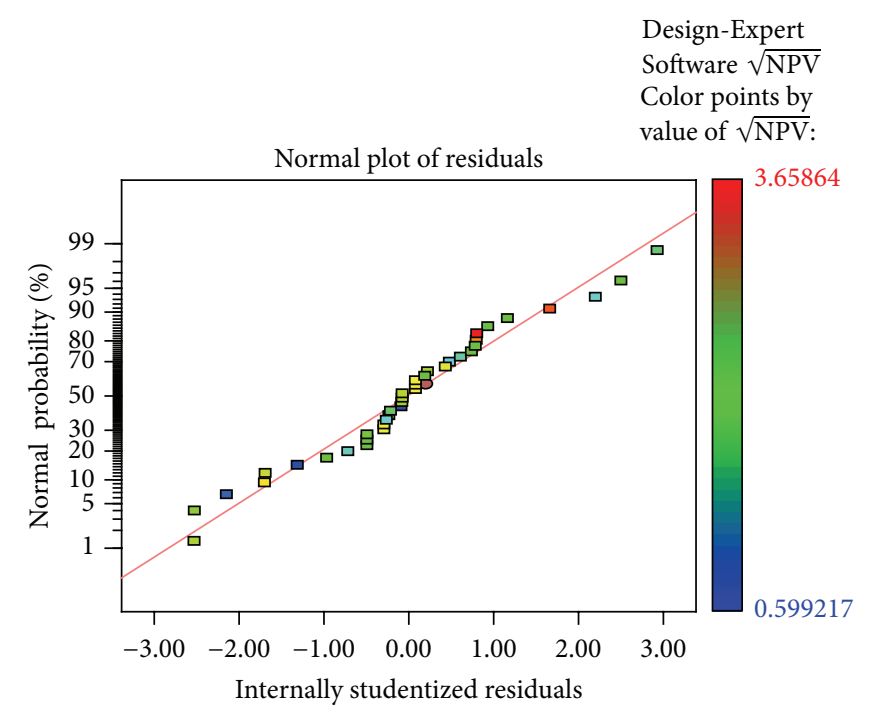

(a) Gas price of $\$ 3 / \mathrm{MSCF}$

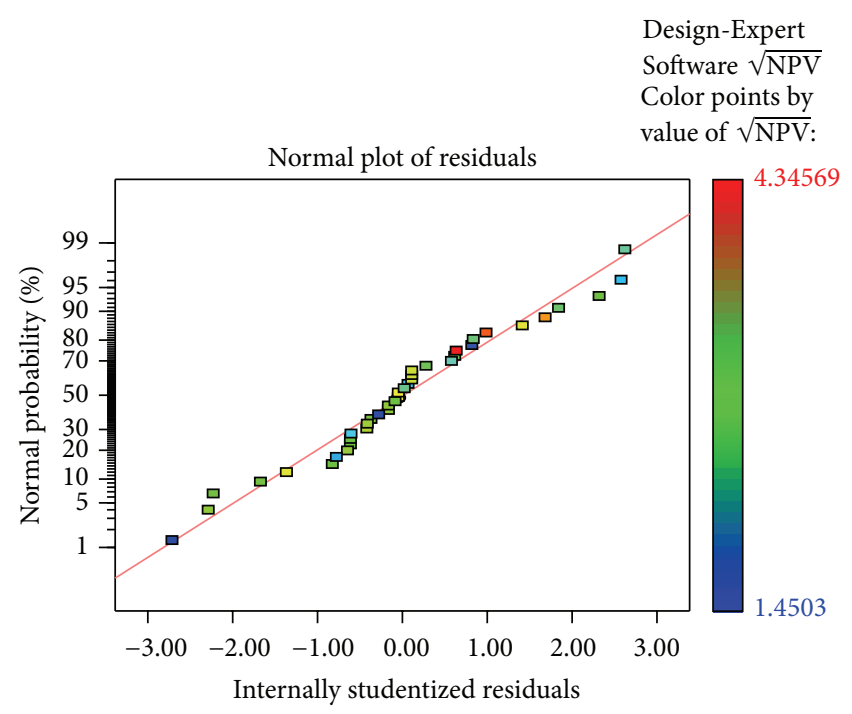

(b) Gas price of $\$ 4 / \mathrm{MSCF}$

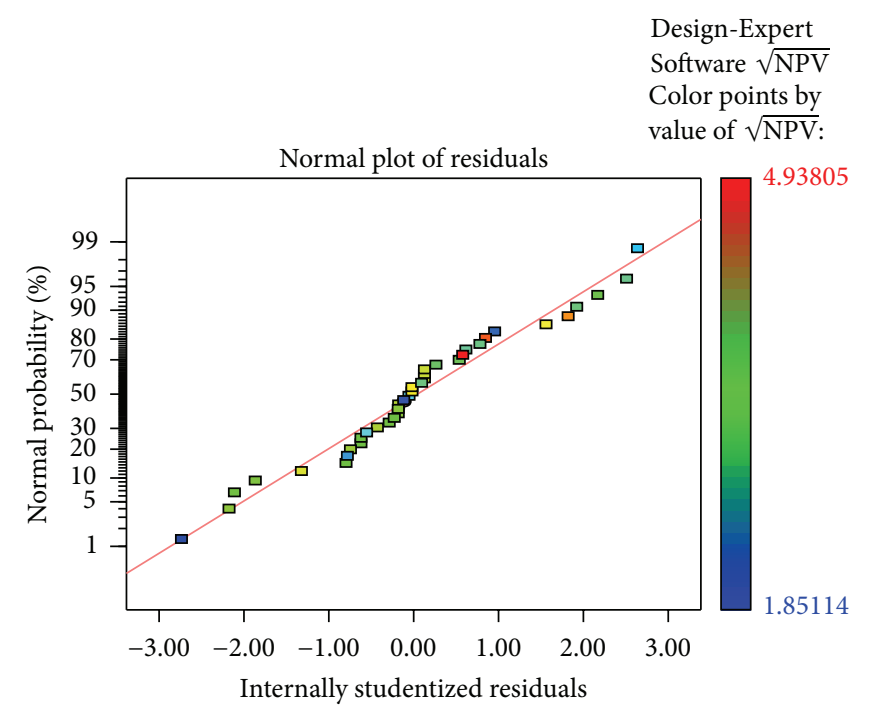

(c) Gas price of $\$ 5 / \mathrm{MSCF}$

FIGURE 12: Normal plot of residuals.

As shown, with the gas production, the gas desorption contributes more due to substantial pressure depletion and larger gas drainage area and finally contributes to $20.7 \%$ of the total gas production at 30 years of gas production. Thus, the impact of gas desorption cannot be ignored when performing history matching and assessing production forecast of gas production in Barnett Shale formation. Hence, this study takes into account gas desorption effect for the subsequent optimization of multiwell placement in Barnett Shale.

\section{Multiwell Modeling}

Two scenarios describing multiple horizontal well placement were studied, as illustrated in Figure 5. Scenario 1 is referred to as aligning fracturing, where hydraulic fracturing is between two wells in an aligned pattern, and Scenario
2 is referred to as alternating fracturing, where hydraulic fracturing is between two wells in a staggered pattern. We investigate the effect of fracture spacing towards comparison of gas production between these two scenarios. We set up a shale gas reservoir model with a volume of $5000 \mathrm{ft} \times$ $1600 \mathrm{ft} \times 200 \mathrm{ft}$. Detailed reservoir information used for Barnett Shale is listed in Table 3. Comparison of cumulative gas production is shown in Figure 6. It shows that there is almost no difference of gas production for these two scenarios when fracture spacing is below $400 \mathrm{ft}$; however, Scenario 2 yields higher gas production than Scenario 1 when the fracture spacing is $400 \mathrm{ft}$ or above. Figure 7 presents the comparison of average reservoir pressure with fracture spacing of $600 \mathrm{ft}$. It can be seen that for Scenario 2, it has a larger average reservoir pressure drawdown, leading to higher cumulative gas production. Pressure distribution at 
TABLE 6: D-Optimal design table.

\begin{tabular}{|c|c|c|c|c|c|c|}
\hline Run & A-Porosity & $\begin{array}{c}B \text {-Permeability } \\
(\mathrm{md})\end{array}$ & $\begin{array}{c}C \text {-Fracture } \\
\text { half-length }(\mathrm{ft})\end{array}$ & $\begin{array}{c}D \text {-Fracture } \\
\text { conductivity (md-ft) }\end{array}$ & $\begin{array}{c}E \text {-Fracture spacing } \\
(\mathrm{ft})\end{array}$ & $\begin{array}{c}F \text {-Well distance } \\
(\mathrm{ft})\end{array}$ \\
\hline 1 & 0.05 & $5.00 E-05$ & 200 & 1 & 40 & 900 \\
\hline 2 & 0.04 & $5.00 E-04$ & 400 & 41 & 100 & 900 \\
\hline 3 & 0.06 & $2.52 E-04$ & 300 & 1 & 60 & 500 \\
\hline 4 & 0.08 & $3.38 E-04$ & 300 & 27 & 40 & 700 \\
\hline 5 & 0.06 & $5.00 E-04$ & 300 & 25 & 80 & 800 \\
\hline 6 & 0.05 & $2.37 E-04$ & 200 & 50 & 40 & 600 \\
\hline 7 & 0.08 & $5.00 E-05$ & 400 & 1 & 40 & 700 \\
\hline 8 & 0.08 & $3.38 E-04$ & 300 & 27 & 40 & 700 \\
\hline 9 & 0.05 & $5.00 E-04$ & 200 & 3 & 100 & 500 \\
\hline 10 & 0.05 & $7.25 E-05$ & 400 & 12 & 100 & 700 \\
\hline 11 & 0.04 & $4.71 E-04$ & 200 & 28 & 40 & 1000 \\
\hline 12 & 0.04 & $4.55 E-04$ & 400 & 41 & 80 & 500 \\
\hline 13 & 0.08 & $5.00 E-05$ & 400 & 50 & 60 & 600 \\
\hline 14 & 0.08 & $5.00 E-04$ & 200 & 50 & 60 & 500 \\
\hline 15 & 0.04 & $3.76 E-04$ & 300 & 1 & 100 & 1000 \\
\hline 16 & 0.08 & $3.20 E-04$ & 400 & 50 & 100 & 1000 \\
\hline 17 & 0.06 & $5.00 E-04$ & 300 & 25 & 80 & 800 \\
\hline 18 & 0.04 & $5.00 E-05$ & 300 & 50 & 60 & 900 \\
\hline 19 & 0.04 & $5.00 E-04$ & 200 & 50 & 100 & 900 \\
\hline 20 & 0.08 & $2.71 E-04$ & 200 & 15 & 80 & 800 \\
\hline 21 & 0.06 & $5.00 E-05$ & 200 & 33 & 100 & 1000 \\
\hline 22 & 0.04 & $5.00 E-05$ & 400 & 26 & 40 & 500 \\
\hline 23 & 0.04 & $5.00 E-04$ & 300 & 9 & 60 & 1000 \\
\hline 24 & 0.08 & $5.00 E-04$ & 200 & 1 & 40 & 1000 \\
\hline 25 & 0.06 & $5.00 E-05$ & 400 & 43 & 40 & 900 \\
\hline 26 & 0.07 & $1.92 E-04$ & 300 & 45 & 100 & 500 \\
\hline 27 & 0.06 & $2.52 E-04$ & 300 & 1 & 60 & 500 \\
\hline 28 & 0.08 & $2.71 E-04$ & 200 & 15 & 80 & 800 \\
\hline 29 & 0.04 & $5.00 E-05$ & 200 & 17 & 80 & 500 \\
\hline 30 & 0.08 & $5.00 E-05$ & 200 & 14 & 40 & 500 \\
\hline 31 & 0.08 & $5.00 E-05$ & 300 & 1 & 100 & 1000 \\
\hline 32 & 0.04 & $5.00 E-04$ & 400 & 1 & 40 & 700 \\
\hline 33 & 0.08 & $5.00 E-04$ & 400 & 1 & 100 & 500 \\
\hline 34 & 0.06 & $5.00 E-04$ & 300 & 25 & 80 & 800 \\
\hline 35 & 0.08 & $5.00 E-05$ & 200 & 50 & 40 & 1000 \\
\hline 36 & 0.08 & $5.00 E-04$ & 400 & 50 & 80 & 600 \\
\hline 37 & 0.06 & $5.00 E-04$ & 400 & 50 & 40 & 1000 \\
\hline 38 & 0.07 & $1.98 E-04$ & 400 & 14 & 60 & 1000 \\
\hline
\end{tabular}

TABLE 7: Statistical approach to select the RSM model with gas price of \$3/MSCF.

\begin{tabular}{lcccccc}
\hline Source & Std. Dev. & $R$-Squared & Adjusted $R$-Squared & Predicted $R$-Squared & Press \\
\hline Linear & 0.27 & 0.8812 & 0.8582 & 0.8094 & 3.72 & - \\
2FI & 0.26 & 0.9433 & 0.8688 & 0.2155 & 15.31 \\
Quadratic & 0.064 & 0.9979 & 0.9921 & 0.9032 & 1.89 \\
Cubic & 0 & 1 & 1 & - & - & Suggested \\
\hline
\end{tabular}




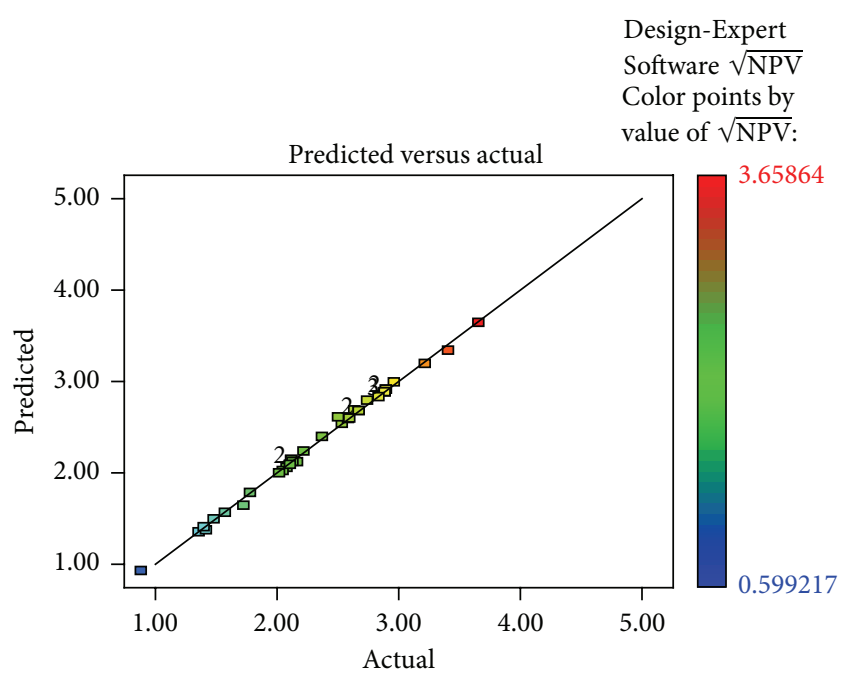

(a) Gas price of $\$ 3 / \mathrm{MSCF}$

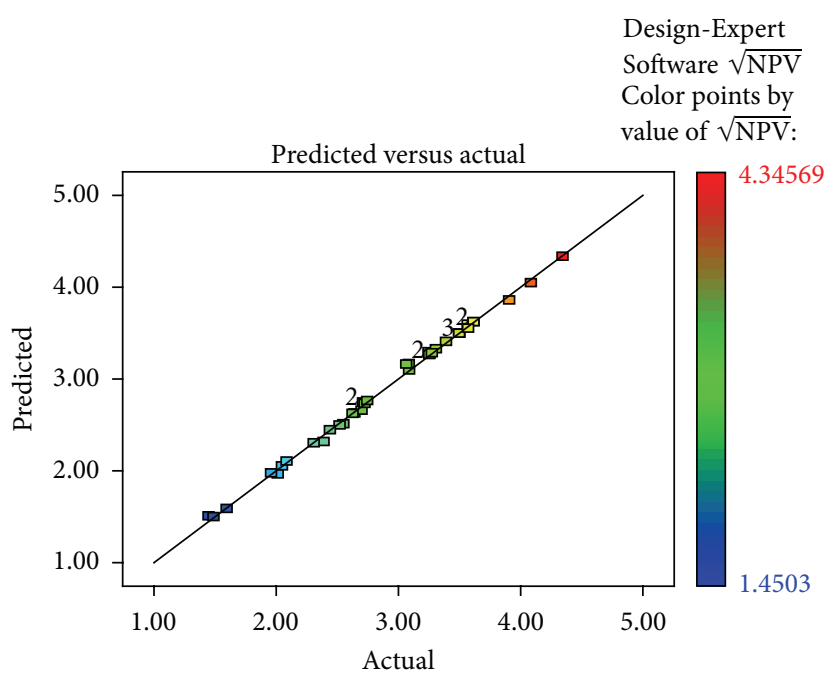

(b) Gas price of $\$ 4 / \mathrm{MSCF}$

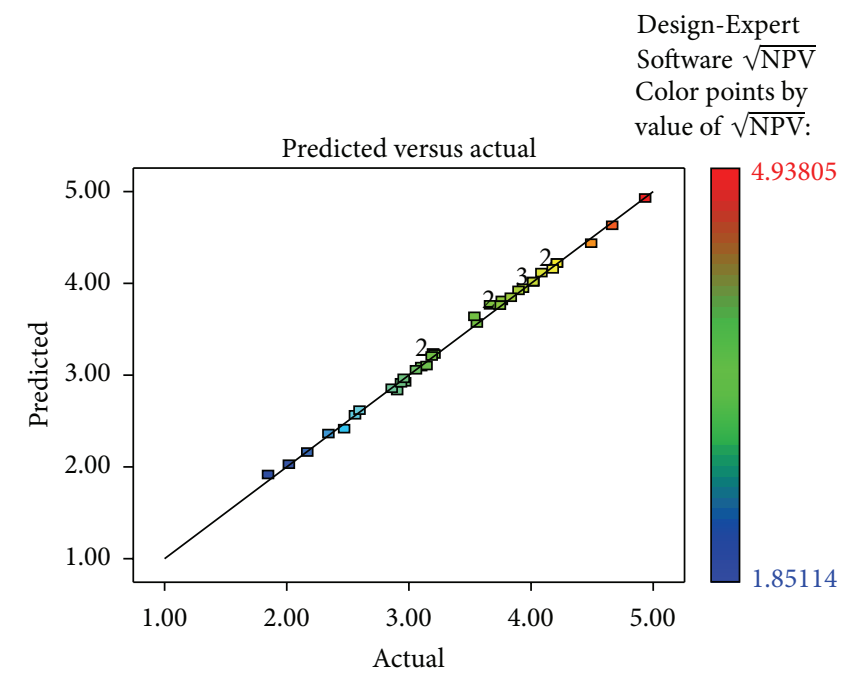

(c) Gas price of $\$ 5 / \mathrm{MSCF}$

FIgURE 13: Predicted NPV versus the actual NPV plot.

TABLE 8: Statistical approach to select the RSM model with gas price of $\$ 4 / \mathrm{MSCF}$.

\begin{tabular}{lcccccc}
\hline Source & Std. Dev. & $R$-Squared & Adjusted $R$-Squared & Predicted $R$-Squared & Press \\
\hline Linear & 0.25 & 0.8950 & 0.8747 & 0.8314 & 3.16 & - \\
2FI & 0.24 & 0.9497 & 0.8837 & 0.2936 & - \\
Quadratic & 0.065 & 0.9978 & 0.9917 & 0.8851 & 2.16 \\
Cubic & 0 & 1 & 1 & - & - & Suggested \\
\hline
\end{tabular}

TABLE 9: Statistical approach to select the RSM model with gas price of $\$ 5 / \mathrm{MSCF}$.

\begin{tabular}{lccccc}
\hline Source & Std. Dev. & $R$-Squared & Adjusted $R$-Squared & Predicted $R$-Squared & Press \\
\hline Linear & 0.26 & 0.8985 & 0.8788 & 0.8368 & 3.37 \\
2FI & 0.25 & 0.9525 & 0.8901 & 0.3213 & 14.01 \\
Quadratic & 0.071 & 0.9975 & 0.9908 & 0.8712 & 2.66 \\
Cubic & 0 & 1 & 1 & - & Suggested \\
\hline
\end{tabular}




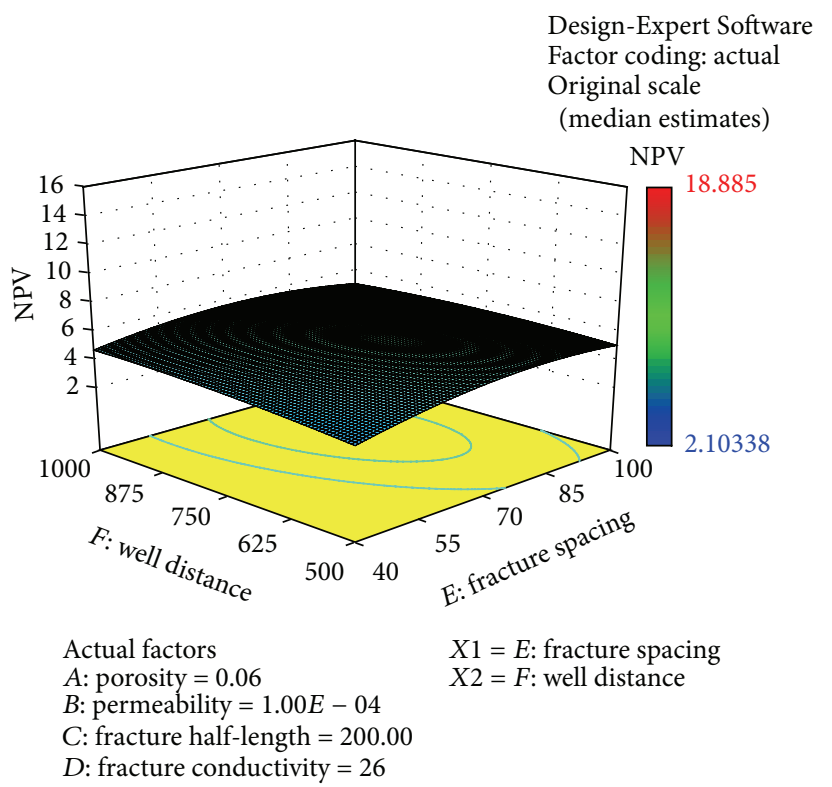

(a) Fracture half-length of $200 \mathrm{ft}$

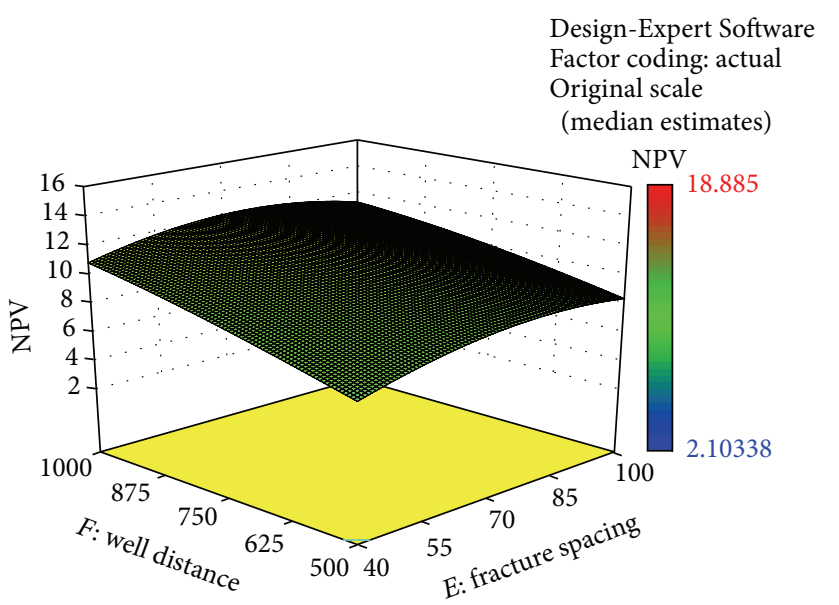

$\begin{array}{ll}\text { Actual factors } & X 1=E: \text { fracture spacing } \\ \text { A: porosity }=0.06 & X 2=F: \text { well distance } \\ \text { B: permeability }=1.00 E-04 & \\ \text { C: fracture half-length }=400.00 & \\ D: \text { fracture conductivity }=26 & \end{array}$

(b) Fracture half-length of $400 \mathrm{ft}$

FIGURE 14: 3D surface of NPV at varied values of well distance and fracture spacing with gas price of \$4/MSCF.

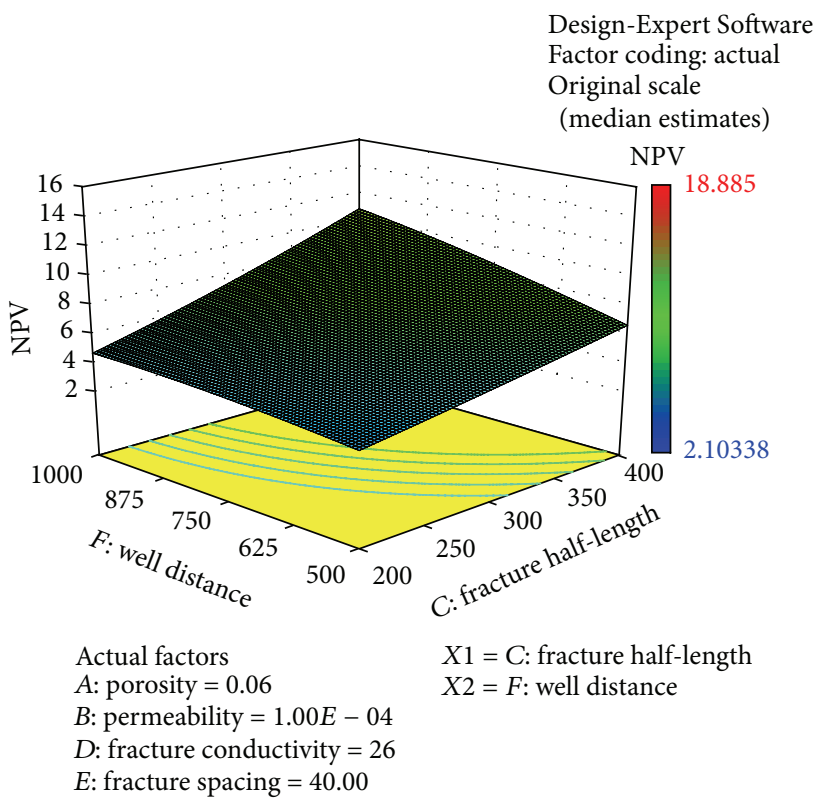

(a) Fracture spacing of $40 \mathrm{ft}$

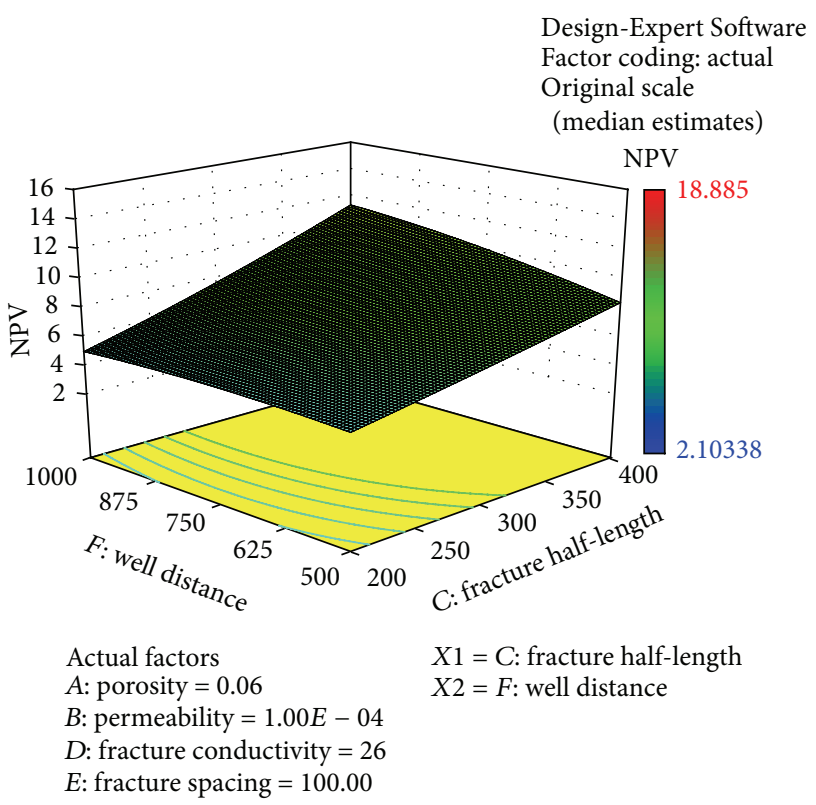

(b) Fracture spacing of $100 \mathrm{ft}$

FIGURE 15: 3D surface of NPV at varied values of well distance and fracture half-length with gas price of \$4/MSCF.

TABLE 10: Optimal combinations and optimization validation.

\begin{tabular}{lccccccccc}
\hline Porosity & $\begin{array}{c}\text { Permeability } \\
(\mathrm{md})\end{array}$ & $\begin{array}{c}\text { Fracture } \\
\text { half-length } \\
(\mathrm{ft})\end{array}$ & $\begin{array}{c}\text { Fracture } \\
\text { conductivity } \\
(\mathrm{md}-\mathrm{ft})\end{array}$ & $\begin{array}{c}\text { Fracture } \\
\text { spacing }(\mathrm{ft})\end{array}$ & $\begin{array}{c}\text { Well } \\
\text { distance }(\mathrm{ft})\end{array}$ & $\begin{array}{c}\text { Gas price } \\
(\$ / \mathrm{MSCF})\end{array}$ & $\begin{array}{c}\text { Optimal } \\
\text { NPV } \\
(\$ \mathrm{MM})\end{array}$ & $\begin{array}{c}\text { Validated } \\
\text { NPV } \\
(\$ \mathrm{MM})\end{array}$ & $\begin{array}{c}\text { Relative } \\
\text { error }\end{array}$ \\
\hline 0.06 & 0.0001 & 400 & 26 & 80 & 1000 & 3 & 8.70 & 7.91 & 0.091 \\
0.06 & 0.0001 & 400 & 26 & 70 & 1000 & 4 & 12.40 & 11.81 & 0.047 \\
0.06 & 0.0001 & 400 & 26 & 60 & 1000 & 5 & 16.34 & 15.75 & 0.036 \\
\hline
\end{tabular}




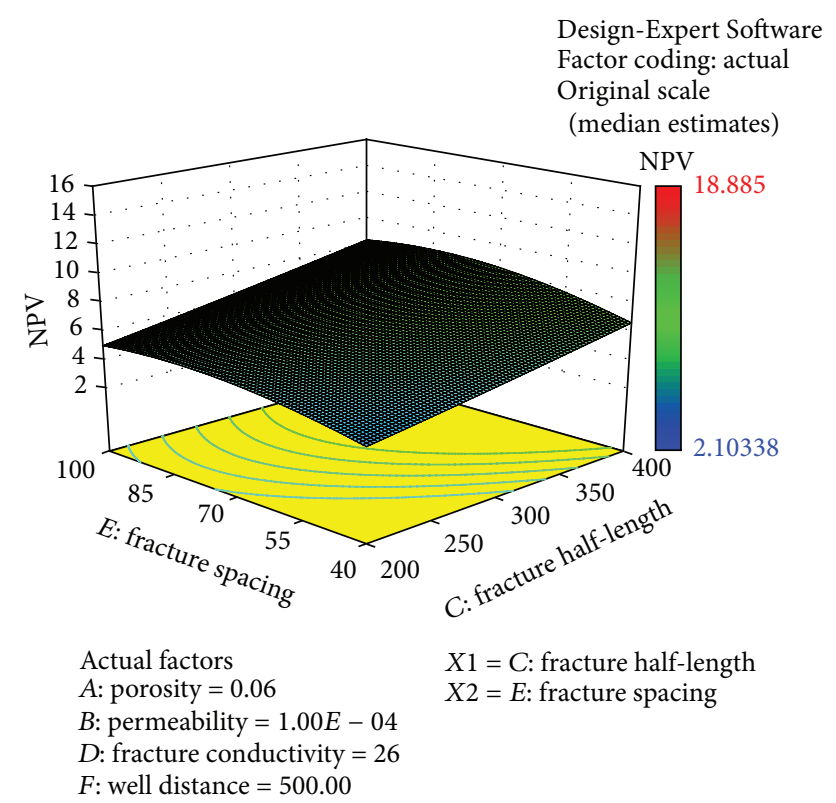

(a) Well distance of $500 \mathrm{ft}$

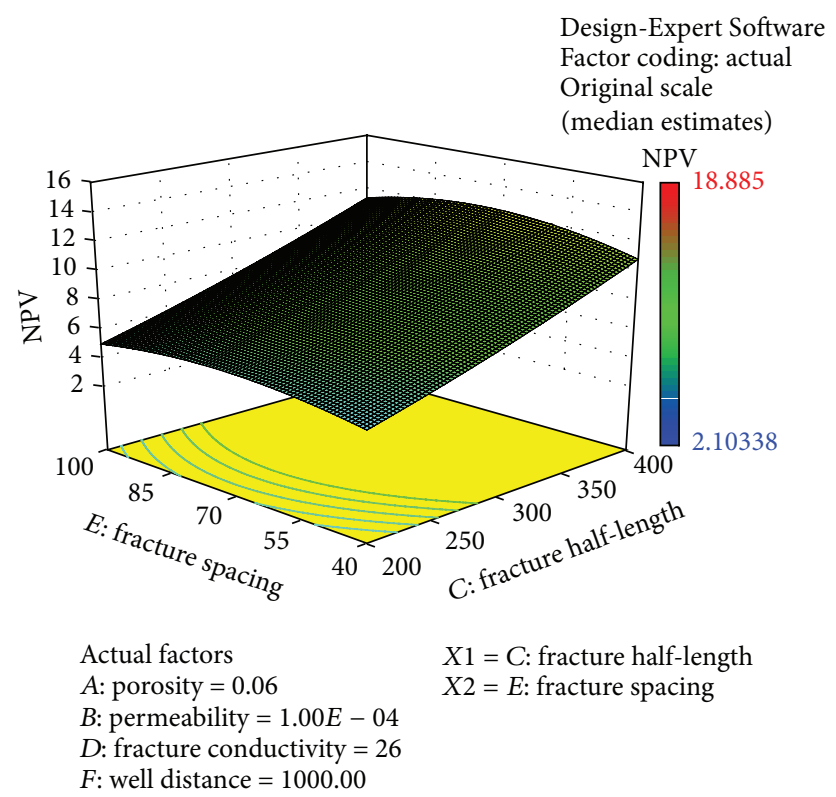

(b) Well distance of $1000 \mathrm{ft}$

FIGURE 16: 3D surface of NPV at varied values of fracture spacing and fracture half-length with gas price of \$4/MSCF.

30 years of gas production for these two scenarios is shown in Figure 8. It shows that more contact reservoir area is drained effectively by Scenario 2, compared to Scenario 1 . In addition, Rafiee et al. [7] reported that Scenario 2 design can increase the stress interference between fractures and create more effective stimulated reservoir volume to improve gas production. Therefore, Scenario 2 is used for optimization of multi-well placement in the subsequent study of this paper.

\section{Multiwell Optimization}

Response surface methodology (RSM) approach is applied to the optimization of two horizontal well placement based on the Barnett Shale reservoir information. RSM is utilized to approximate a response, in terms of maximum NPV in this work, over a region of interest specified by the range of variability of input factors based on the least squares criterion. The RSM model can be linear or fully quadratic. It can offer a cost-effective and efficient way to manage the uncertainties for shale gas reservoir development. More detailed mathematical and statistical theories of RSM can be found in the work by Myers and Montgomery [21]. We set up a shale gas reservoir model with a volume of $5000 \mathrm{ft} \times$ $2000 \mathrm{ft} \times 200 \mathrm{ft}$. Detailed reservoir information used for the Barnett Shale is listed in Table 4. Six uncertain parameters such as porosity $(A)$, permeability $(B)$, fracture half-length $(C)$, fracture conductivity $(D)$, fracture spacing $(E)$, and well distance $(F)$ are given a reasonable range with the actual maximum and minimum values or coded symbol of “ +1 ” and "-1," respectively, as shown in Table 5. The number of hydraulic fractures is 87 and 35 , corresponding to fracture spacing of $40 \mathrm{ft}$ and $100 \mathrm{ft}$, respectively. These uncertainty ranges come from field data, analogues, and history matching of the Barnett Shale reservoirs. According to 6 variables, 38 cases were required, based on the approach of D-Optimal design, which was originated from the optimal design theory [22]. Table 6 shows the 38 combinations of these uncertain parameters generated by the D-Optimal design. After numerical simulation of each case, cumulative gas production and gas flow rate are obtained and shown in Figures 9 and 10 for selected cases with various fracture spacing and fracture halflength. It clearly shows that the cumulative gas production at 30 years of gas production is in the range of 3934-6529 MMSCF and gas flow rate has a large uncertainty. This means further optimization is needed.

Once the cumulative gas production of 38 run cases obtained, the economic Excel spreadsheet is used to calculate the corresponding NPVs. In this work, the impact of different gas price is considered for calculation of NPVs and optimization of fracturing design in multi-well placement to determine the optimal stimulation design. The price of natural gas plays a critical role in economic success of shale gas development. The activity in shale gas exploitation increases with the increasing gas price. Negative NPV of the project suggests that an unoptimized shale gas production can result in not only no income but also loss of money. For gas price of $\$ 3 / \mathrm{MSCF}$, $4 / \mathrm{MSCF}$, and $\$ 5 / \mathrm{MSCF}$, the positive NPV is in the range of \$0.36-13.39 million, \$2.1018.88 million, and $\$ 3.42-24.38$ million, respectively, as shown in Figure 11.

Once NPVs of 38 run cases obtained, the Design-Expert Software is used to build the NPV response surface model in this study. To select the appropriate model, the statistical approach was used to determine which polynomial fits the equation among linear model, two-factor interaction model (2FI), quadratic model, and cubic model, as shown 


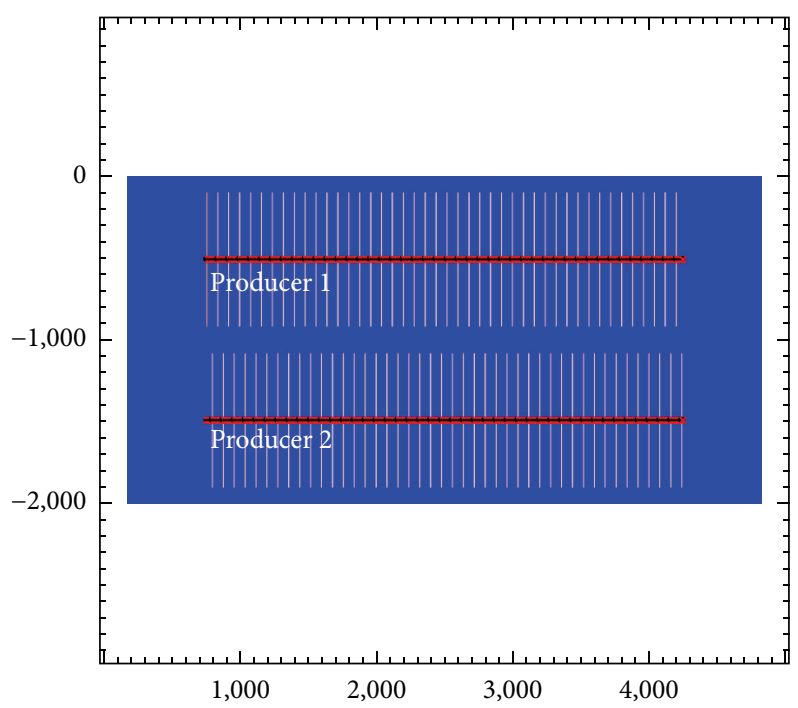

(a) Fracture spacing of $80 \mathrm{ft}$ for gas price of $\$ 3 / \mathrm{MSCF}$

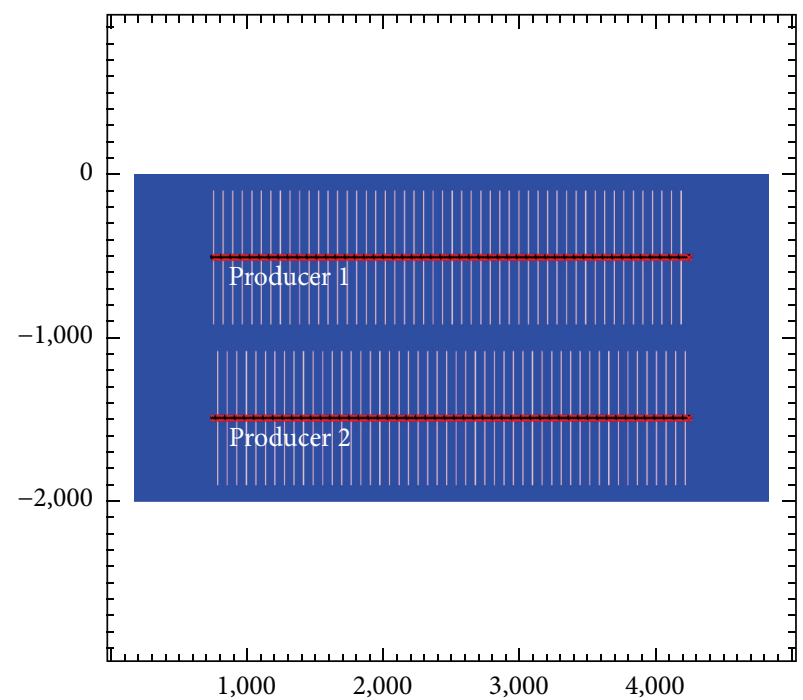

(b) Fracture spacing of $70 \mathrm{ft}$ for gas price of $\$ 4 / \mathrm{MSCF}$

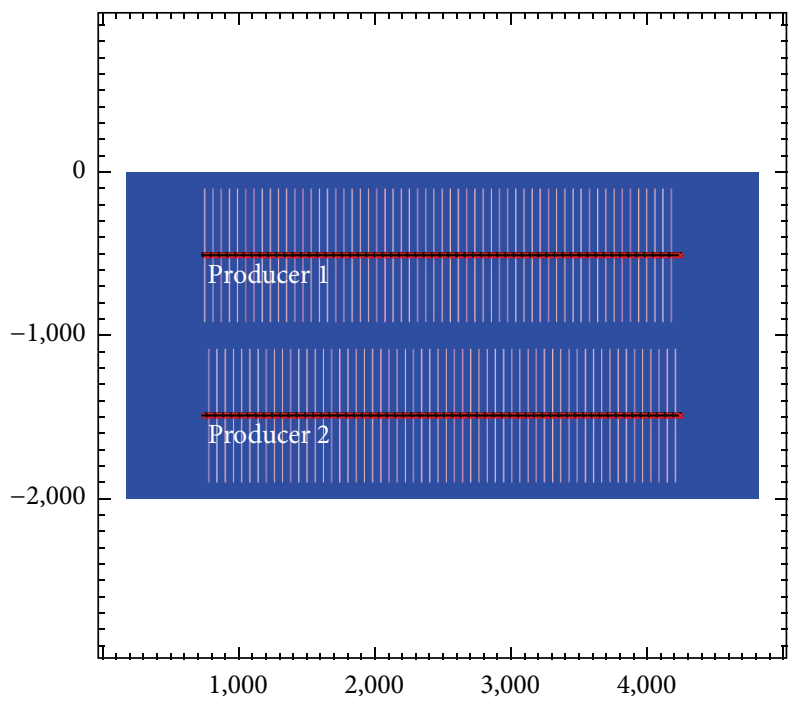

(c) Fracture spacing of $60 \mathrm{ft}$ for gas price of $\$ 5 / \mathrm{MSCF}$

FIGURE 17: The optimum fracture spacing with different gas prices.

in Tables 7, 8, and 9, for different gas prices. The criterion for selecting the appropriate model is choosing the highest polynomial model, where the additional terms are significant and the model is not aliased. Although the cubic model is the highest polynomial model, it is not selected because it is aliased. Aliasing is a result of reducing the number of experimental runs. When it occurs, several groups of effects are combined into one group and the most significant effect in the group is used to represent the effect of the group. Essentially, it is important that the model is not aliased. In addition, other criteria are to select the model that has the maximum "Adjusted $R$-Squared" and "Predicted $R$ Squared". Thus, the fully quadratic model is selected to build the NPV response surface in the subsequent optimization process.
The equation fitted to the NPV response surface with the coded symbol for different gas prices is presented below.

For gas price of $\$ 3 / \mathrm{MSCF}$,

$$
\begin{aligned}
\sqrt{\mathrm{NPV}}= & 2.67+0.59 \times A+0.35 \times B+0.35 \times C \\
& +0.056 \times D+0.21 \times E+0.170 \times F-0.025 \times A B \\
& +0.058 \times A C-0.011 \times A D-0.160 \times A E \\
& -0.037 \times A F-0.090 \times B C-0.026 \times B D \\
& -0.028 \times B E-0.0056 \times B F+0.15 \times C D \\
& +0.0098 \times C E+0.13 \times C F+0.046 \times D E \\
& +0.044 \times D F-0.064 \times E F-0.086 \times A^{2}
\end{aligned}
$$




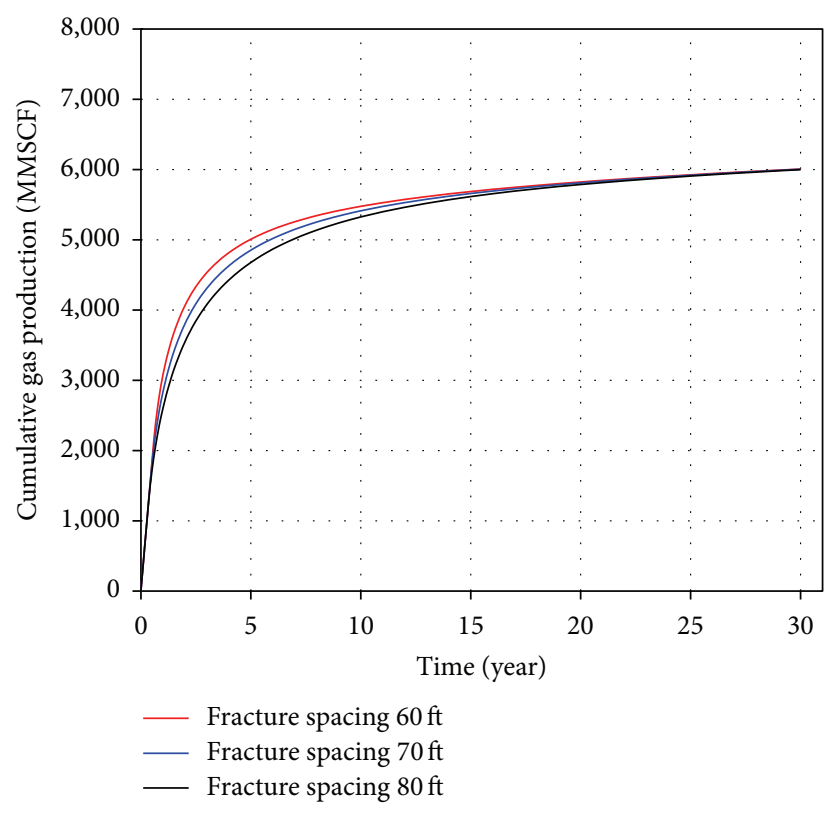

(a) Cumulative gas production

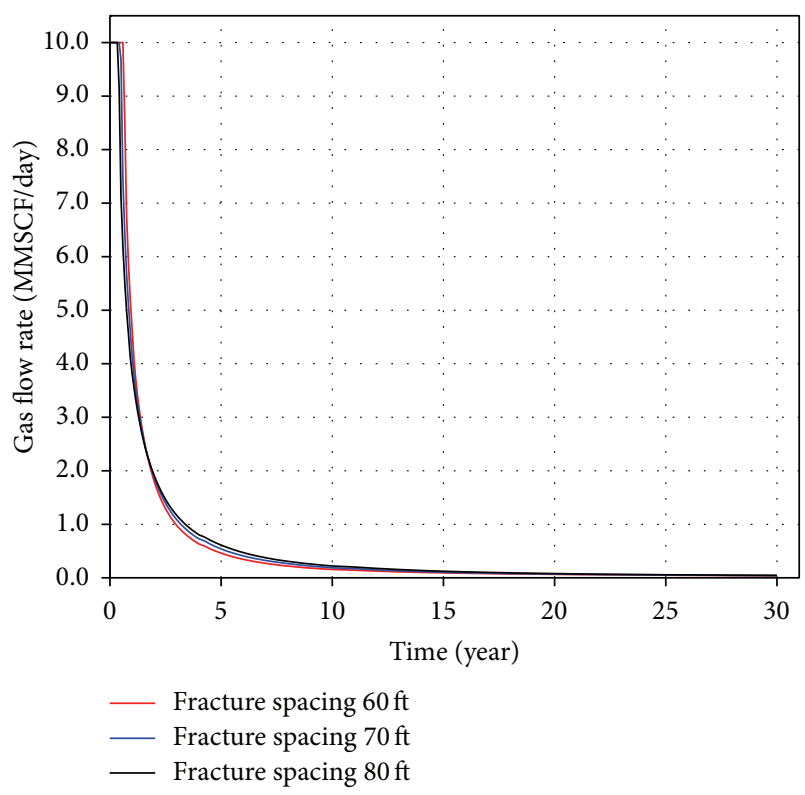

(b) Gas flow rate

FIGURE 18: Three optimum cases with different fracture spacing for different gas prices.

$$
\begin{aligned}
& -0.24 \times B^{2}-0.013 \times C^{2}-0.069 \times D^{2} \\
& -0.25 \times E^{2}-0.057 \times F^{2} .
\end{aligned}
$$

For gas price of $\$ 4 / \mathrm{MSCF}$,

$$
\begin{aligned}
\sqrt{\mathrm{NPV}}= & 3.27+0.60 \times A+0.35 \times B+0.38 \times C \\
& +0.050 \times D+0.12 \times E+0.190 \times F+0.014 \times A B \\
& +0.055 \times A C+0.018 \times A D-0.11 \times A E \\
& -0.018 \times A F-0.088 \times B C-0.0012 \times B D \\
& +0.028 \times B E+0.011 \times B F+0.020 \times C D \\
& +0.0014 \times C E+0.12 \times C F+0.055 \times D E \\
& +0.027 \times D F-0.062 \times E F-0.082 \times A^{2} \\
& -0.25 \times B^{2}-0.0083 \times C^{2}-0.094 \times D^{2} \\
& -0.19 \times E^{2}-0.062 \times F^{2}
\end{aligned}
$$

For gas price of $\$ 5 / \mathrm{MSCF}$,

$$
\begin{aligned}
\sqrt{\mathrm{NPV}}= & 3.78+0.63 \times A+0.37 \times B+0.410 \times C \\
& +0.053 \times D+0.070 \times E+0.20 \times F \\
& +0.027 \times A B+0.060 \times A C+0.027 \times A D \\
& -0.096 \times A E-0.011 \times A F-0.091 \times B C \\
& +0.0042 \times B D+0.046 \times B E+0.017 \times B F
\end{aligned}
$$

$$
\begin{aligned}
& +0.021 \times C D-0.00061 \times C E+0.13 \times C F \\
& +0.062 \times D E+0.024 \times D F-0.063 \times E F \\
& -0.083 \times A^{2}-0.26 \times B^{2}-0.0052 \times C^{2} \\
& -0.11 \times D^{2}-0.17 \times E^{2}-0.07 \times F^{2}
\end{aligned}
$$

where $A$ is formation porosity; $B$ is formation permeability, md; $C$ is fracture half-length, $\mathrm{ft} ; D$ is fracture conductivity, $\mathrm{md}-\mathrm{ft}$; $E$ is fracture spacing, $\mathrm{ft} ; F$ is well distance, $\mathrm{ft}$.

The normal plot of residuals, reflecting the distribution of the residuals, for different gas prices is shown in Figure 12. All the points in the "Normal Plot of Residuals" fall on the straight line, meaning the residuals are normally distributed. Figure 13 shows the plot of "Predicted versus Actual" for different gas prices, illustrating whether the generated equation of NPV response surface accurately predicts the actual NPV values. It can be seen that generated NPV response surface models provide such reliable predicted values of NPV, as compared with the actual values of NPV. This means that the generated NPV response surface models are reliable.

Figure 14 shows the 3D surface of the well distance and fracture spacing with gas price of \$4/MSCF. It shows that there exists an optimal combination between well distance and fracture spacing. For fracture half-length of $200 \mathrm{ft}$, the NPV first increases and then decrease with increasing well distance. For fracture half-length of $400 \mathrm{ft}$, the NPV increases with increasing well distance within the range of this study. With the increasing fracture half-length, the optimal point moves to larger well distance. Figure 15 presents the $3 \mathrm{D}$ surface of the well distance and fracture half-length with gas price of $\$ 4 / \mathrm{MSCF}$. It can be seen that larger well distance 
and fracture half-length will lead to higher NPV. Similarly, Figure 16 presents the 3D surface of the fracture spacing and fracture half-length with gas price of \$4/MSCF. It shows that there exists an optimal value for fracture spacing. With the increasing well distance, the optimal point moves to larger fracture half-length and smaller fracture spacing. Therefore, it can provide some insights into optimization of stimulation designs and completion strategies to obtain the maximum economic viability of the field.

The numerical optimization option selects the set of variables that leads to the maximum NPV value. In this study for the Barnett Shale, the optimal designs with porosity of 0.06 and permeability of $0.0001 \mathrm{md}$ and different gas prices are listed in Table 10. The optimal NPV value is $\$ 8.70 \mathrm{MM}, \$ 12.40 \mathrm{MM}$, and $\$ 16.34 \mathrm{MM}$, for gas price of $\$ 3 / \mathrm{MSCF}, \$ 4 / \mathrm{MSCF}$, and $\$ 5 / \mathrm{MSCF}$, respectively. What is more, the optimal fracture spacing is $80 \mathrm{ft}$ for gas price of $\$ 3 / \mathrm{MSCF}, 70 \mathrm{ft}$ for gas price of $\$ 4 / \mathrm{MSCF}$, and $60 \mathrm{ft}$ for gas price of $\$ 5 / \mathrm{MSCF}$, as shown in Figure 17 . It is extremely vital to validate the optimal results. Verification is performed by running the simulation with the best design condition. Figure 18 shows the cumulative gas production and gas flow rate for these three optimum cases with different gas prices, respectively. The NPV is calculated as $\$ 7.91 \mathrm{MM}, \$ 11.81 \mathrm{MM}$, and $\$ 15.75 \mathrm{MM}$, for gas price of $\$ 3 / \mathrm{MSCF}$, $\$$ /MSCF, and $\$ 5 / \mathrm{MSCF}$, respectively. The absolute NPV difference between the NPV from the response surface and the real NPV is small. As indicated by the small relative error, all three solutions show a very good agreement between the calculated NPV and the real NPV.

\section{Summary and Conclusions}

The economic success of shale gas reservoirs depends on optimization of the number of treatment stages and number of fractures and horizontal wells. In this paper, response surface methodology was used to obtain the optimal design for shale gas production by optimizing reservoir and fracture uncertainty parameters in two horizontal wells. We applied this method to optimize 6 uncertain parameters, such as permeability, porosity, fracture spacing, fracture half-length, fracture conductivity, and well distance for the Barnett Shale development. Also, the gas desorption effect is considered for modeling shale gas production because of its large contribution to the estimated ultimate recovery for the Barnett Shale. The impact of varying natural gas price is taken into account during the optimization process. The following conclusions can be drawn from this study.

(1) With a porosity of 0.06 , a permeability of $0.0001 \mathrm{md}$, and a fracture conductivity of $26 \mathrm{md}-\mathrm{ft}$, the optimal design combinations for Barnett Shale is fracture half-length of $400 \mathrm{ft}$, well distance of $1000 \mathrm{ft}$, and fracture spacing of $80 \mathrm{ft}, 70 \mathrm{ft}$, and $60 \mathrm{ft}$ for gas price of $\$ 3 / \mathrm{MSCF}$, \$4/MSCF, and \$5/MSCF, respectively.

(2) The gas desorption contributes to $20.7 \%$ of EUR at 30 years of gas production for an actual Barnett Shale horizontal well.
(3) The proposed approach is practical and efficient for the design and optimization of hydraulic fracturing for multiple horizontal wells in shale gas reservoirs.

\section{Nomenclature}

$\begin{array}{ll}\text { DoE: } & \text { Design of experiment } \\ \text { RSM: } & \text { Response surface methodology } \\ \text { 2FI: } & \text { Two-factor interaction } \\ \text { EUR: } & \text { Estimated ultimate recovery } \\ \text { SCF: } & \text { Standard cubic feet, } \mathrm{ft}^{3} \\ \text { NPV: } & \text { Net present value } \\ \text { MSCF: } & 10^{3} \text { standard cubic feet, } \mathrm{ft}^{3} \\ \text { MMSCF: } & 10^{6} \text { standard cubic feet, } \mathrm{ft}^{3} \\ \beta: & \text { Non-Darcy Beta factor, } \mathrm{ft}^{-1} \\ K: & \text { Permeability, md } \\ P: & \text { Present value, } \$ \\ F: & \text { Future value, } \$ \\ i: & \text { Currency escalation rate } \\ n: & \text { Number of periods, year } \\ V_{F}: & \text { Future value of production revenue for a } \\ V_{o}: & \text { fracture reservoir, } \$ \\ \text { FC: } & \text { Future value of production revenue for an } \\ C_{\mathrm{well}}: & \text { unfractured reservoir, } \$ \\ C_{\mathrm{fracture}}: & \text { Total fixed cost, } \$ \\ N: & \text { Cost of one horizontal well, } \$ \\ V_{L}: & \text { well, } \$ \\ P_{L}: & \text { Number of horizontal wells } \\ G_{s}: & \text { Langmuir pressure, scf/ton } \\ \rho_{B}: & \text { Langmuir volume, psi } \\ & \text { Gas content, scf/ton } \\ & \text { Bulk density of shale, g/cm }{ }^{3} .\end{array}$

\section{Acknowledgments}

Funding for this project is provided by the Hilcorp Energy Company. The authors would like to acknowledge Computer Modeling Group Ltd. for providing with usage of CMGIMEX software. The authors would also like to express their gratitude for reviewers for their careful review of this paper.

\section{References}

[1] J. L. Miskimins, "Design and life-cycle considerations for unconventional-reservoir wells," SPE Production and Operations, vol. 24, no. 2, pp. 353-359, 2009.

[2] G. Waters, B. Dean, R. Downie, K. Kerrihard, L. Austbo, and B. McPherson, "Simultaneous hydraulic fracturing of adjacent horizontal wells in the woodford shale," in Proceedings of the SPE Hydraulic Fracturing Technology Conference, pp. 694-715, Woodlands, Tex, USA, January 2009.

[3] M. J. Kaiser, "Haynesville shale play economic analysis," Journal of Petroleum Science and Engineering, vol. 82-83, pp. 75-89, 2012.

[4] S. L. Montgomery, D. M. Jarvie, K. A. Bowker, and R. M. Pollastro, "Mississippian Barnett Shale, Fort Worth basin, north-central Texas: gas-shale play with multi-trillion cubic foot potential," AAPG Bulletin, vol. 89, no. 2, pp. 155-175, 2005. 
[5] M. Segatto and I. Colombo, "Use of reservoir simulation to help gas shale reservoir estimation," in Proceedings of the International Petroleum Technology Conference (IPTC '11), Bangkok, Thailand, 2011.

[6] S. Esmaili, A. Kalantari-Dahaghi, and S. D. Mohaghegh, "Modeling and history matching of hydrocarbon production from Marcellus shale using data mining and pattern recognition technologies," in Proceedings of the SPE Eastern Regional Meeting (SPE '12), Lexington, Ky, USA, 2012.

[7] M. Rafiee, M. Y. Soliman, and E. Pirayesh, "Hydraulic fracturing design and optimization: a modification to zipper frac," in Proceedings of the SPE Eastern Regional Meeting (SPE '12), Lexington, Ky, USA, 2012.

[8] O. C. Díaz de Souza, A. J. Sharp, R. C. Martinez et al., "Integrated unconventional shale gas reservoir modeling: a worked example from the Haynesville Shale, De Soto Parish, North Lousiana," in Proceedings of the Americas Unconventional Resources Conference (SPE '12), Pittsburgh, Pa, USA, 2012.

[9] J. Harpel, L. Barker, J. Fontenot, C. Carroll, S. Thomson, and K. Olson, "Case history of the Fayetteville shale completions," in Proceedings of the SPE Hydraulic Fracturing Technology Conference (SPE '12), The Woodlands, Tex, USA, 2012.

[10] H. Ramakrishnan, R. Yuyan, and J. Belhadi, "Real-time completion optimization of multiple laterals in gas shale reservoirs: Integration of geology, log, surface seismic, and microseismic information," in Proceedings of the SPE Hydraulic Fracturing Technology Conference, pp. 691-705, The Woodlands, Tex, USA, January 2011.

[11] S. Tavassoli, W. Yu, F. Javadpour, and K. Sepehrnoori, "Well screen and optimal time of refracturing: a Barnett shale well," Journal of Petroleum Engineering, vol. 2013, pp. 1-10, 2013.

[12] W. Yu and K. Sepehrnoori, "Simulation of gas desorption and geomechanics effects for unconventional gas reservoirs," in Proceedings of the SPE Western Regional and AAPG Pacific Section Meeting (SPE '13), Monterey, Calif, USA,, 2013.

[13] W. Yu and K. Sepehrnoori, "An efficient reservoir simulation approach to design and optimize unconventional gas production," in Proceedings of the SPE Western Regional and AAPG Pacific Section Meeting (SPE '13), Monterey, Calif, USA,, 2013.

[14] B. Rubin, "Accurate simulation of non-darcy flow in stimulated fractured shale reservoirs," in Proceedings of the SPE Western Regional Meeting (SPE '10), pp. 19-34, Anaheim, Calif, USA, May 2010.

[15] C. L. Cipolla, E. P. Lolon, J. C. Erdle, and B. Rubin, "Reservoir modeling in shale-gas reservoirs," SPE Reservoir Evaluation and Engineering, vol. 13, no. 4, pp. 638-653, 2010.

[16] R. D. Evans and F. Civan, "Characterization of non-Darcy multiphase flow in petroleum bearing formations," U.S. DOE Contract DE-AC22-90BC14659, School of Petroleum and Geological Engineering, University of Oklahoma, 1994.

[17] R. Schweitzer and H. I. Bilgesu, "The role of economics on well and fracture design completions of marcellus shale wells," in Proceedings of the SPE Eastern Regional Meeting (SPE '09), pp. 423-428, September 2009.

[18] CMG, IMEX User's Guide, Computer Modeling Group, 2011.

[19] J. P. Seidle and L. E. Arri, "Use of conventional reservoir models for coalbed methane simulation," in Proceedings of the CIM/SPE International Technical Meeting (SPE '90), Calgary, Canada, 1990.

[20] H. A. Al-Ahmadi, S. Aramco, and R. A. Wattenbarger, “Tripleporosity models: one further step towards capturing fractured reservoirs heterogeneity," in Proceedings of the SPE/DGS Saudi Arabia Section Technical Symposium and Exhibition (SPE '11), Al-Khobar, Saudi Arabia, 2011.

[21] R. H. Myers and D. C. Montgomery, Response Surface Methodology: Process and Product Optimization Using Designed Experiments, John Wiley and Sons, Hoboken, NJ, USA, 2002.

[22] J. Kiefer and J. Wolfowitz, "Optimum designs in regression problems," The Annals of Mathematical Statistics, vol. 30, no. 2, pp. 271-294, 1959. 

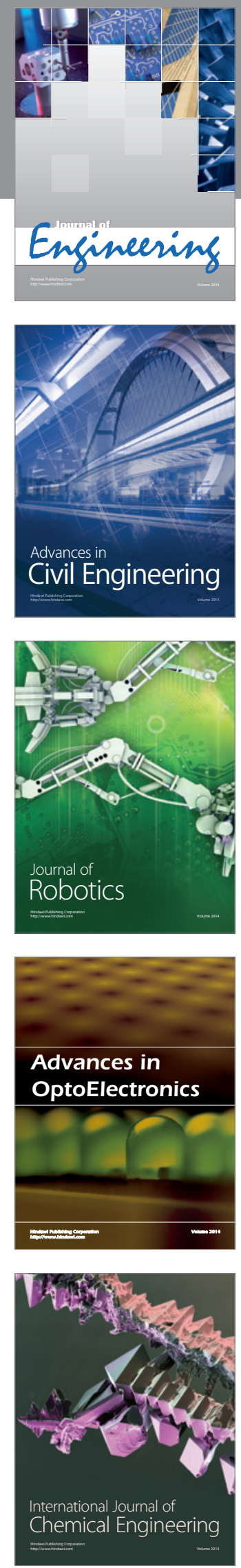

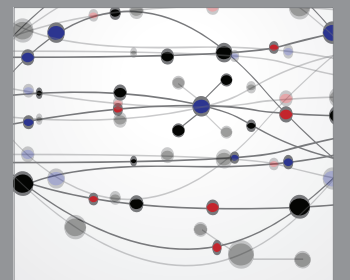

The Scientific World Journal
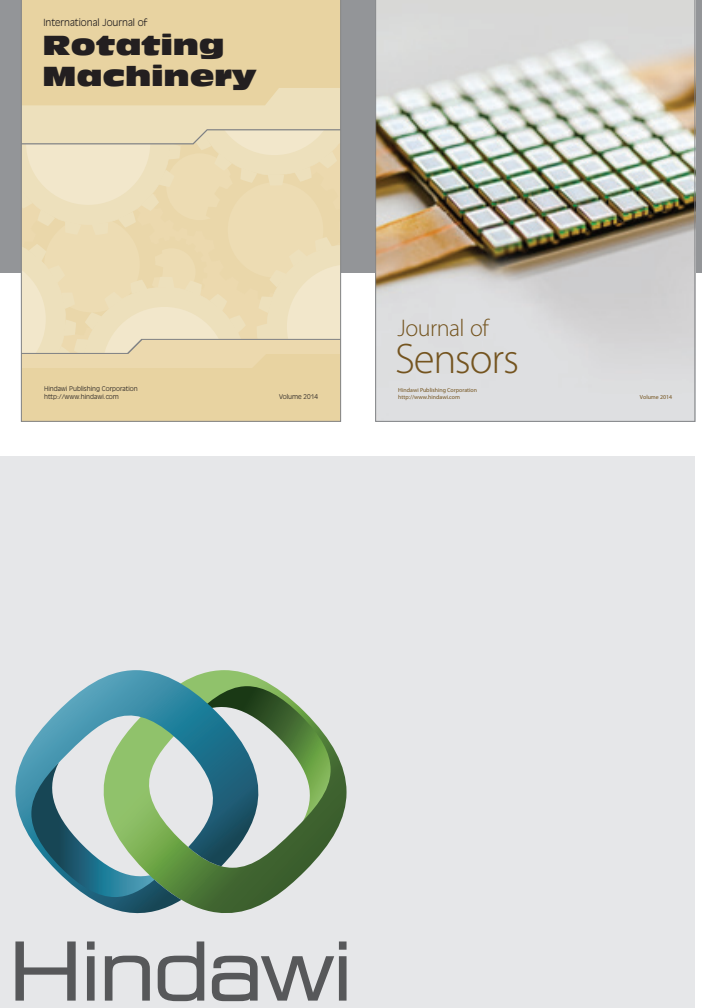

Submit your manuscripts at http://www.hindawi.com
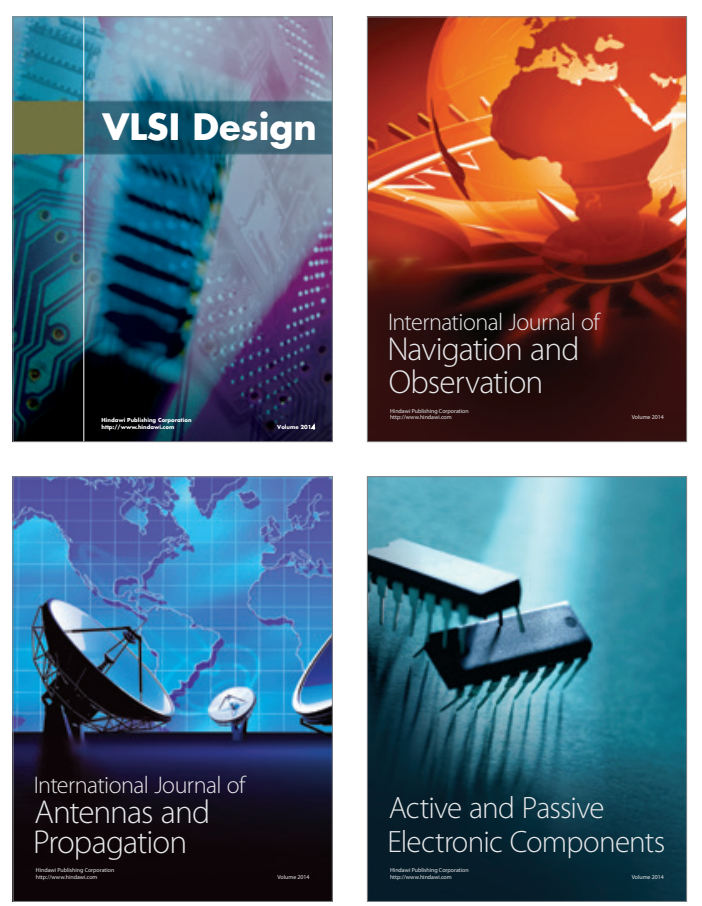
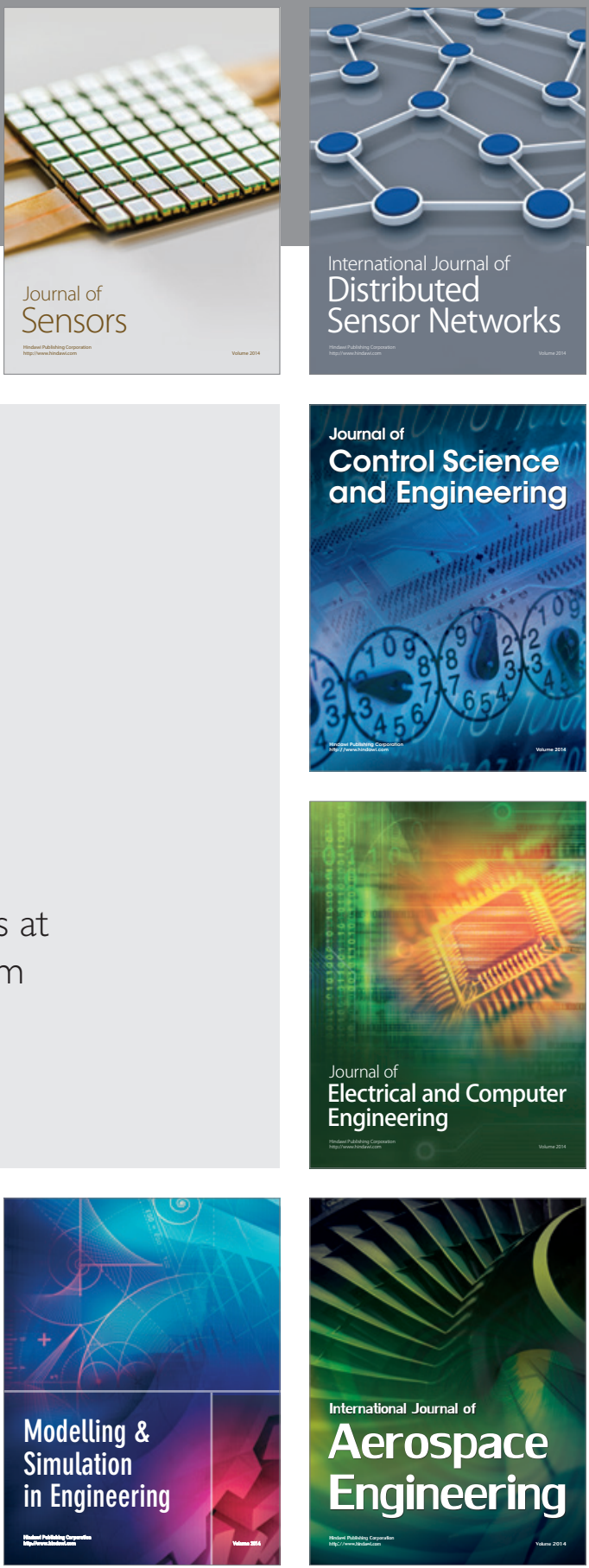

Journal of

Control Science

and Engineering
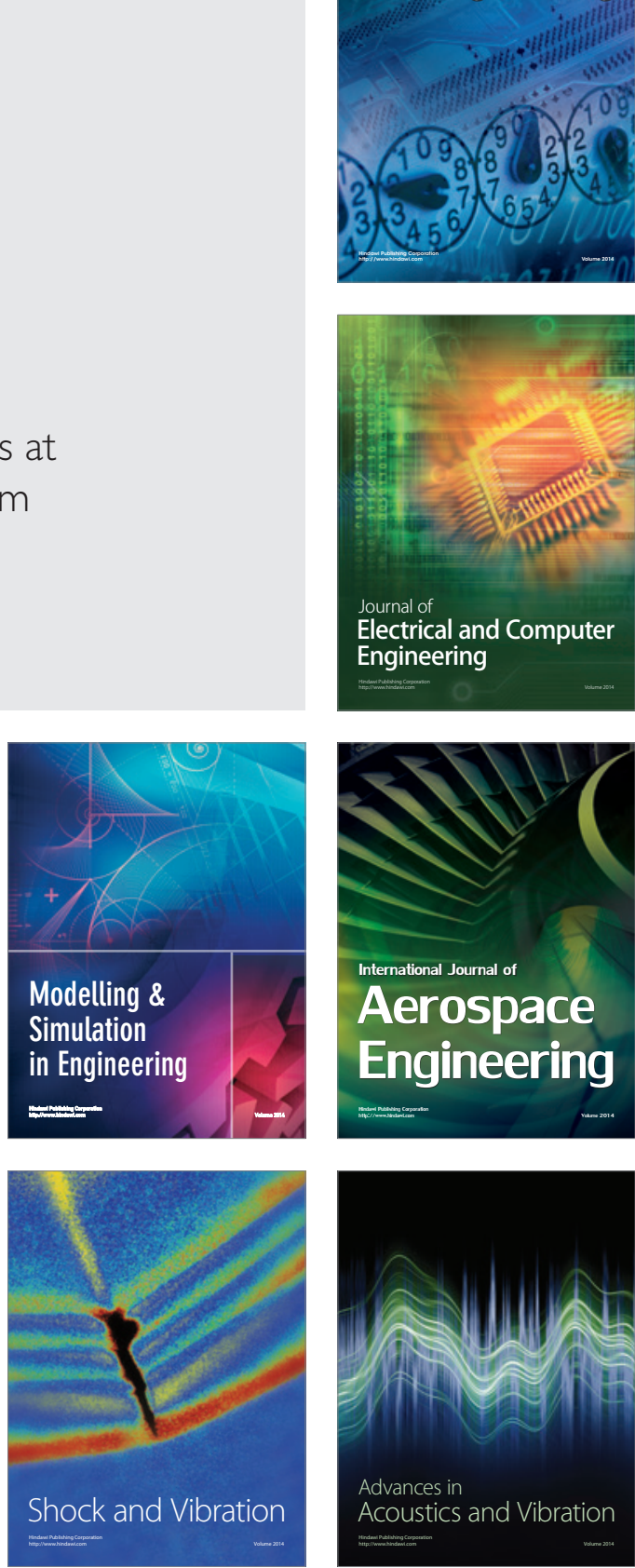